Revista de Estudios Histórico-Jurídicos

[Sección derecho romano] XLIII (Valparaíso, Chile, 2021) [pp. 107-134]

\title{
LA DECLARACIÓN DEL ESTADO DE EMERGENCIA FRENTE A LAS EPIDEMIAS EN LA REPÚBLICA ROMANA
}

[The emergency decree during the epidemic in the Roman Republic]

\author{
Alejandro Valiño Arcos* \\ Universitat de València, España
}

\section{Resumen}

El artículo tiene por objeto el estudio a través de la historiografía clásica de las medidas extraordinarias adoptadas en la República romana en situaciones de epidemia, con especial referencia a dos instrumentos jurídico-religiosos ordenados a aplacar la cólera divina: el lectisternium y la dictadura clavi figendi causa.

Palabras Clave

lectisternium - dictator - lex de clavo pangendo-dictatura clavi figendi causa - clavus annalis.
Abstract

The paper aims at the study through the classical sources the extraordinary measures taken in the roman republic in the case of epidemic, paying special attention to some legal-religious actions in order to soften the divine rage: the lectisternium and the dictatura clavi figendi causa.

\section{KEY WORDS}

lectisternium - dictator - lex de clavo pangendo - dictatura clavi figendi causa - clavus annalis.

RECIBIDO el 21 de junio de 2020 y ACEPTADO el 17 de marzo de 2021

* Catedrático de Derecho Romano en la Facultad de Derecho de la Universitat de València. Dirección postal: Avda. dels Tarongers s/n, 46022 Valencia, España. Correo electrónico: alejandro.valino@uv.es Número ORCID: 0000-0002-2523-0975. 


\section{Armazón institucional de LA República ROMANA}

El régimen político romano que más se asemeja al nuestro es la República. En su momento de esplendor, una vez superados los titubeantes primeros momentos de transición tras el derrocamiento del último de los Reyes de Roma, Tarquinio el Soberbio, en el 509 a. C., puede hablarse de un sólido armazón integrado por tres elementos. En primer término, el elemento aristocrático, representado por el Senado, al que competía trazar las grandes líneas de la política internacional en un momento político en el que Roma apuesta por la expansión y, con ella, por la creación de nuevos núcleos urbanos que replican el modelo institucional y organizativo de la Urbs, desde la centuriación del territorio y su asignación a los veteranos allí desplazados, hasta la disposición urbanística, concretada en la erección de edificios civiles y religiosos, imprescindible en el proceso de asimilación ciudadana romana.

En segundo lugar, el elemento autocrático, representado por los magistrados, de distintas categorías y con diferente ámbito competencial, si bien siempre supeditados en el ejercicio de su función ejecutiva a las directrices marcadas por el Senado, ante quien estaban llamados a rendir cuentas de su gestión una vez completado el ejercicio de su magistratura, por principio, no sin excepciones, anual y sometida al freno de la intercessio derivada del desempeño de forma colegiada de las funciones que les eran propias. Por último, el elemento democrático, representado por el Populus romanus, que también contribuye a esa mediatización del poder de los magistrados, a quienes eligen anualmente en los comicios y cuyas iniciativas normativas (rogationes) pueden apoyar o rechazar.

\section{LA QUIEBRA DEL EQUILIBRIO INSTITUCIONAL REPUBLICANO PARA HACER} FRENTE A COYUNTURAS EXTRAORDINARIAS

Este escenario un tanto idílico, consolidado desde mediados del siglo IV a. C. tras superar los convulsos momentos del estreno de la nueva forma política, no es obstáculo para que, ocasionalmente, la República haya tenido que apartarse de este juego de contrapesos para conferir temporalmente el máximo poder político a personajes carismáticos en momentos de alteración y calamidad pública, como el que pueden generar las epidemias, que están desde luego muy presentes en la historiografía romana de todo género. En efecto, la literatura greco-latina está plagada de referencias a las epidemias ${ }^{1}$. Los términos latinos más recurrentes para

${ }^{1}$ Gardner, Hunter H., Pestilence and the body politic in latin literature (Oxford, Oxford University Press, 2019), pp. 17 ss., abunda en el sentido metafórico de enfermedad en el contexto político, al que recurren con frecuencia autores de la antigüedad como Tucídides y Cicerón para describir situaciones de conflicto político-social. También están reflejadas en no pocas inscripciones. $V i d$. al respecto Kunschwitz, Peter, Eine kleine Poetik der Seuche. Epidemien im Spiegel römischer Verinschriften, en Gymnasium 127/2 (2020), pp. 137 ss. 
designarlas son pestis $^{2}$ y sus derivados pestilentia ${ }^{3}$ y pestilitas ${ }^{4}$. También comparecen términos como morbus ${ }^{5}$, contagio ${ }^{6}$ o lues $^{7}$.

Así, Lucrecio, poeta del siglo I a.C., se detenía en su obra de rerum Natura en sus causas y procedencia, venidas unas veces del cielo, otras surgidas de la propia tierra por la acción de agentes meteorológicos como la lluvia o el calor ${ }^{8}$. Las había

${ }^{2}$ Se identifica con enfermedad contagiosa o con una atmósfera o clima insano, así como, por extensión, con destrucción, ruina o muerte. Incluso, en ocasiones, se califica así a cosas o personas por su potencia destructiva. Entre las muchísimas referencias en el Thesaurus Linguae Latinae, puede citarse Plaut. Capt. 4, 3, 3: “quanta pernis pestis veniet?”; 3, 3, 11: "quin male occidam oppetamque pestem eri vicem meamque"; Plaut. Asin. 1, 1, 7: "atque illa viva vivos ut pestem oppetas"; Plaut. Pseud. 1, 2, 70: “quin una omnes peste hac populum hunc liberant?"; Cic. nat. deor. 1, 101: “ibes [...] avertunt pestem ab Aegypto"; Cic. Off. 2, 5, 16: "atque ut magnas utilitates adipiscimur conspiratione hominum atque consensu, sic nulla tam detestabilis pestis est, quae non homini ab homine nascatur"; Cic. Rab. Perd. 1, 2: "nibil consensio bonorum contra pestem ac perniciem civitatis valeret"; Cic. Deiot. 43: "quocirca, C. Caesar, velim existimes hodierno die sententiam tuam aut cum summo dedecore miserrimam pestem importaturam esse regibus aut incolumem famam cum salute"; Cic. Sest. 14, 33: "ab illa furia ac peste patriae" (calificativo que se hace de Clodio); Cic. Verr. 2, 3, 54, 125: "nunc autem ne post abitum quidem huius importunissimae pestis quisquam reperiretur qui sua voluntate araref"; Cic. Fam. 5, 8, 2: “sed quaedam pestes hominum laude aliena dolentium et te nonnumquam a me alienarunt et me aliquando immutarunt tibi"; Liv. 4, 25, 3: "multa duumviri ex libris placandae deum irae avertendaeque a populo pestis causa fecere"; Liv. 5, 14, 3-4: "pestilentiam agris urbique inlatam haud dubia ira deum, quos pestis eius arcendae causa placandos esse in libris fatalibus inventum sit”; Liv., 25, 19, 17: "ceteri passim alii alia peste absumpti sint”; Cat. 69, 9: "quare aut crudelem nasorum interfice pestem/ aut admirari desine cur fugiunt"; Col. RR. 7, 5, 19: "quod in omnibus morbis ac pestibus fieri debere censemus"; Verg. Aen. 5, 699: "servatae a peste carinae"; Verg. Aen. 3, 214: "nec saevior ulla / pestis et ira deum"; Verg. Aen. 6, 737: "corporae [...] pestes"; Verg. Georg. 1, 181: "variae [...] pestes"; Juv. 4, 84: "si clade et peste sub illa saeuitiam damnare et honestum adferre liceret" (sobre Nerón).

${ }^{3}$ Como enfermedad contagiosa comparece en Caes. B. C. 2, 22: "massilienses omnibus defessi malis, rei frumentariae ad summam inopiam adducti, bis navali proelio superati, crebris eruptionibus fusi, gravi etiam pestilentia conflictati [...]"; Cic. Off. 2, 5, 16: "atque ut magnas utilitates adipiscimur conspiratione hominum atque consensu, sic nulla tam detestabilis pestis est, quae non homini ab homine nascatur"; y Liv. 27, 23: "eo anno pestilentia gravis incidit in urbem agrosque, quae tamen magis in longos morbos quam in permitiales euasit". Como sinónimo de plaga o peste, puede verse en Cat. 44, 11: "orationem in Antium petitorem / plenam veneni et pestilentiae leg?"; y en Gell. 1, 2, 4: "rem vero ethicam naturamque bumani ingenii virtutumque origines officiaque earum et confinia aut contra morborum vitiorumque fraudes animorumque labes, pestilentias asseverabat nulli esse ulli magis ea omnia explorata comperta meditataque". También se emplea en relación con un clima o zona insalubre en Cic. Leg. Agr. 2, 26, 70: "alterum genus agrorum propter sterilitatem incultum, propter pestilentiam vastum atque desertum emetur ab eis qui eos vident sibi esse, si non vendiderint, relinquendos"; y Cic. Div. 1, 57, 131: "Democritus autem censet sapienter instituisse veteres ut hostiarum immolatarum inspicerentur exta; quorum ex habitu atque ex colore tum salubritatis, tum pestilentiae signa percipi, non numquam etiam quae sit vel sterilitas agrorum vel fertilitas futura".

${ }^{4}$ Lucr. 6, 1098: "atque ea vis omnis morborum pestilitasque / aut extrinsecus ut nubes nebulaeque superne / per caelum veniunt"; 1125: "baec igitur subito clades nova pestilitasque / aut in aquas cadit aut fruges persidit in ipsas / aut alios hominum pastus pecudumque cibatus"; y 1132: "consimili ratione venit bubus quoque saepe / pestilitas et iam pigris balantibus aegror".

${ }^{5}$ Designa una enfermedad, desorden o afección tanto corporal como mental. Así lo expresa Cic. Tusc. 4, 13, 28: "morbum appellant totius corporis corruptionem, aegrotationem morbum cum imbecillitate, vitium, cum partes corporis inter se dissident, ex quo pravitas membrorum, distortio, deformitas". Existen infinidad de referencias textuales que nos brindan una noción que, ciertamente, trasciende de 
que se daban en ciertos territorios, las había también que incidían en determinados órganos del cuerpo ${ }^{9}$, pero, con independencia del lugar de residencia, cualquiera quedaba expuesto a sus funestas consecuencias, pues Lucrecio ponía el acento en la intervención del aire como agente que posibilita su propagación, corrompiendo

la especificidad propia de las epidemias y sus devastadores efectos sobre el conjunto de una o varias comunidades políticas.

${ }^{6} \mathrm{El}$ término contagio es el más genuino, pero no faltan referencias a contagium entre poetas y escritores postaugusteos. Muy numerosas son las referencias al término contagio en sus distintas acepciones, tanto como mero 'contacto' como, sobre todo, en una dimensión negativa que lo identifica con polución, contamina ción o infección, acepción ésta que es extensiva a las relaciones humanas. Vid. entre otros Cic. Nat. Deor. 2, 55, 138: “illa potius explicetur incredibilis fabrica naturae: nam quae spiritu in pulmones anima ducitur, ea calescit primum ipso ab spiritu, deinde contagione pulmonum, ex eaque pars redditur respirando, pars concipitur cordis parte quadam, quam ventriculum cordis appellant, cui similis alter adiunctus est, in quem sanguis a iecore per venam illam cavam influit"; Cic. Div. 1, 30, 63: "cum ergo est somno sevocatus animus a societate et a contagione corporis, tum meminit praeteritorum, praesentia cernit, futura providet; iacet enim corpus dormientis ut mortui, viget autem et vivit animus"; Cic. Fat. 3, 5: "quorum in aliis, ut in Antipatro poeta, ut in brumali die natis, ut in simul aegrotantibus fratribus, ut in urina, ut in unguibus, ut in reliquis eius modi, naturae contagio valet, quam ego non tollo--vis est nulla fatalis"; Cic. de Orat. 3, 41, 164: "melius esset vetas, probibes, absterres; quoniam ille dixerat: ilico istic, ne contagio mea bonis umbrave obsit [...]"; Cic. Mur. 37, 78: "latius patet illius sceleris contagio quam quisquam putat, ad pluris pertinet. Intus, intus, inquam, est equus Troianus; a quo numquam me consule dormientes opprimemini"; Cic. Sull. 2, 6: "in hoc crimine non solum levitatis est culpa verum etiam quaedam contagio sceleris, si defendas eum quem obstrictum esse patriae parricidio suspicere"; Cic. Att. 1, 16, 3: "pauci tamen boni inerant, quos reiectione fugare ille non potuerat, qui maesti inter sui dissimiles et maerentes sedebant et contagione turpitudinis vehementerpermovebantur"; Cic. Verr. 2, 5, 3, 6: "utrum aditum facilem hostibus an contagionem imitandi belli periculosam fuisse?" y 2, 5, 71, 183: "deliberatum autem est, si res opinionem meam quam de vobis babeo fefellerit, non modo eos persequi ad quos maxime culpa corrupti iudici, sed etiam illos ad quos conscientiae contagio pertinebit"; Cic. Clu. 68, 193: "itaque nullo in oppido consistendi potestas ei fuit, nemo ex tot bospitibus inventus est qui non contagionem aspectus fugeret: nocti se potius ac solitudini quam ulli aut urbi aut hospiti committebal"; Cic. Off. 2, 23, 80: "nec vero solum ipsa cecidit, sed etiam reliquam Graeciam evertit contagionibus malorum, quae a Lacedaemoniis profectae manarunt latius". También tenemos múltiples referencias en Liv. 2, 37, 7; 5, 6, 11; 5, 12, 7; 9, 1, 6; 10, 18, $2 ; 28,24,10 ;$ y 40, 20, 6 .

${ }^{7}$ Ovid. Met. 15, 626: "dira lues quondam Latias vitiaverat auras, / pallidaque exsangui squalebant morbo"; Verg. Aen. 3, 139: "corrupto caeli tractu, miserandaque venit / arboribusque satisque lues et letifer annus"; Luc. 2, 199: "aut coeli terraeque lues, aut bellica clades". En sentido figurado, también se encuentra en Tac. Hist. 3, 15: "et Britannia Galliaque et Hispania auxilia Vitellius acciverat, immensam belli luem, ni Antonius id ipsum metuens festinato proelio victoriam praecepissel"; Tac. Ann. 2, 47: "asperrima in Sardianos lues plurimum in eosdem misericordiae traxit: nam centies sestertium pollicitus Caesar, et quantum aerario aut fisco pendebant in quinquennium remisit"; Sen. Phoen. 131: "adverte mentem, saeva Thebarum lues luctifica caecis verba committens modis quid simile posnit?"; y Val. Flac. 4, 431: "spes una seni, quod pellere saevam quondam fata luem dederant Aquilone creatis".

${ }^{8}$ Lucr. 6, 1090-1102: "nunc ratio quae sit morbis aut unde repente / mortiferam possit cladem conflare coorta / morbida vis hominum generi pecudumque catervis, / expediam, primum multarum semina rerum / esse supra docui quae sint vitalia nobis, / et contra quae sint morbo mortique necessest / multa volare; ea cum casu sunt forte coorta / et perturbarunt caelum, fit morbidus aeër. / Atque ea vis omnis morborum pestilitasque I aut extrinsecus ut nubes nebulaeque superne / per caelum veniunt aut ipsa saepe coorta / de terra surgunt, ubi putorem umida nactast / intempestivis pluviisque et solibus icta".

${ }^{9}$ Lucr. 6, 1116-1118: "inde aliis alius locus est inimicus / partibus ac membris; varius concinnat id aeër". 
las aguas, cultivos y alimentos tanto de hombres como de animales ${ }^{10}$, de modo que el contagio se daba tanto si uno se desplazaba al foco de la epidemia como si ésta, a la que nuestro organismo no estaba adaptado, arribaba para poner a prueba a toda la comunidad ${ }^{11}$. Así, nadie escapaba a la funesta acción de la epidemia por más prevenciones que pudieran adoptarse, que eran presentadas por Lucrecio como manifestaciones de un egoísmo que traía igualmente por recompensa la muerte, que calificaba de mala y deshonrosa ${ }^{12}$. No faltan en él tampoco las referencias a las exequias fúnebres, despojadas de su característico ritual en momentos ${ }^{13}$ en los que ninguna familia escapaba a la pandemia ${ }^{14}$. La sintomatología que refería Lucrecio al describir la epidemia que asoló Atenas al comienzo de la guerra del Peloponeso recuerda mucho la propia del Covid-19: calentura, enrojecimiento ocular, palidez, afecciones varias de una garganta ennegrecida para descender a través de ella al pecho ${ }^{15}$, desencadenando en el paciente una asfixia insoportable que, ante la impotencia de unos médicos también expuestos al contagio $^{16}$, terminaba por dejar el cuerpo exánime en ocho o nueve días ${ }^{17}$. No está el relato poético, por consiguiente, privado de una cierta dimensión naturalistica o sanitaria, en palabras de Riccardo Cardilli, por más que, siguiendo la estela de Tucídides y el episodio de la peste del 430 a. C., se haga especialmente hincapié en las consecuencias económicas y políticas y, en definitiva, incertidumbre vital para el conjunto de la ciudadanía ${ }^{18}$.

Los instrumentos para solventar las grandes amenazas para la estabilidad del

${ }^{10}$ Lucr. 6, 1118-1132: “proinde ubi se caelum, quod nobis forte alienum, / commovet atque aeër inimicus serpere coepit, / ut nebula ac nubes paulatim repit et omne / qua graditur conturbat et immutare coactat, / fit quoque ut, in nostrum cum venit denique caelum, / corrumpat reddatque sui simile atque alienum. / Haec igitur subito clades nova pestilitasque / aut in aquas cadit aut fruges persidit in ipsas / aut alios hominum pastus pecudumque cibatus, / aut etiam suspensa manet vis aeëre in ipso / et, cum spirantes mixtas binc ducimus auras, / illa quoque in corpus pariter sorbere necessest. / Consimili ratione venit bubus quoque saepe I pestilitas et iam pigris balantibus aegror".

${ }^{11}$ Lucr. 6, 1132-1136: "nec refert utrum nos in loca deveniamus / nobis adversa et caeli mutemus amictum, / an caelum nobis ultro natura corumptum / deferat aut aliquid quo non consuevimus uti, / quod nos adventu possit temptare recenti".

${ }^{12}$ Lucr. 6, 1240: "turpi morte malaque".

${ }^{13}$ Lucr. 6, 1278-1279: "nec mos ille sepulturae remanebat in urbe, / quo prius hic populus semper consuerat bumari".

${ }^{14}$ Lucr. 6, 1251-1254: “praeterea iam pastor et armentarius omnis / et robustus item curvi moderator aratri / languebat, penitusque casa contrusa iacebant / corpora paupertate et morbo dedita morti”.

${ }^{15}$ Lucr. 6, 1145-1153: "principio caput incensum fervore gerebant / et duplicis oculos suffusa luce rubentes. / Sudabant etiam fauces intrinsecus atrae / sanguine et ulceribus vocis via saepta coibat / atque animi interpres manabat lingua cruore / debilitata malis, motu gravis, aspera tactu. / Inde ubi per fauces pectus complerat et ipsum / morbida vis in cor maestum confluxerat aegris, / omnia tum vero vitai claustra lababant".

${ }^{16}$ Lucr. 6, 1177-1179: "mussabat tacito medicina timore".

${ }^{17}$ Lucr. 6, 1193-1195: “octavoque fere candenti lumine solis / aut etiam nona reddebant lampade vitam”.

${ }^{18}$ CARDILLI, Riccardo, Emergenza e diritto. Il problema della dittattura romana, en CARDILLI, Riccardo; Ciaccia, Mario; Mirabelli, Cesare (a cura di), Istituzioni, economia, sviluppo. Vecchie e nuovi problema nel dopo emergenza, (Roma, Universitalia, 2020), p. 26. 
orden republicano fueron la dictadura ${ }^{19}$ y el senadoconsulto último ${ }^{20}$, pero estos remedios también podrían entrañar amenaza y riesgo para la estabilidad del orden constitucional. En este sentido, con base en Cicerón, son de rabiosa actualidad las palabras de Álvaro d’Ors: “como el mismo Cicerón nos dice, la concentración del

\footnotetext{
${ }^{19} \mathrm{La}$ bibliografía es, desde luego, inabordable por lo que me limito a señalar unas pocas referencias: Mommsen, Theodor, Römisches Staatsrecht (Dritte Auflage, Leipzig, Verlag von S. Hirzel, 1887), II, 1, pp. 141 ss.; Greenidge, Abel Hendy Jones, Roman public life (New York, MacMillan and Co., Limited, 1901), pp. 191 ss.; Liebenam, Wilhelm, Dictator, en PWRE., (Stuttgart, J. B. Metzlerscher Verlag, 1903), I, col. 370 ss.; WILCKEN, Ulrich, Zur Entwicklung der römischen Diktatur, en Abhandlungen der Preußischen Akademie der Wissenschaften. PhilosophischHistorische Klasse (Berlin, Akademie der Wissenschaften, de Gruyter in Kommission, 1940), I, pp. 3 ss.; Luzzatto, Giuseppe Ignazio, Appunti sulle dittature imminuto iure, en Studi in onore di Pietro de Francisci (Milano, Giuffrè Editore, 1956), III, pp. 405 ss.; DE Martino, Francesco, Storia della costituzione romana (Seconda edizione, Napoli, Casa Editrice Eugenio Jovene, 1972), I, pp. 236-250, 275-285 y 438-452; Sснмiтт, Carl, La dittatura. Dalle origini dell'idea moderna di sovranità alla lotta di classe proletaria (Roma-Bari, Universale Laterza, 1975); IRMSCHER, Johannes, La dittatura. Tentativo di una storia concettuale, en Meloni, Giovanni (a cura di), Dittatura degli antichi e dittatura dei moderni (Roma, Editori Riuniti, 1985), pp. 55 ss.; Cassola, Franco; LabrunA, Luigi, Il dittattore ed il magister equitum, en Talamanca, Mario (dir.), Lineamenti di storia del diritto romano (Seconda ed., Milano, Giuffrè Editore, 1989), pp. 164 ss.; DulckeIT, Gerhard, Schwarz, Fritz, Waldstein, Wolfgang, Römische Rechtsgeschichte (Neunte Auflage, Munich, C. H. Beck'sche Verlagsbuchhandlung, 1995), p. 39; Nicolet, Claude, Dictatorship in Rome, en BAEHr, Peter; Richter, Melvin (ed.) Dictatorship in History and Theory. Bonapartism, Caesarism and Totalitarianism (Whashington D. C., Cambridge University Press, 2004), pp. 263 ss.; Espitia Garzón, Fabio, Dictadura, estado de sitio y provocatio ad populum en la obra de Mommsen, en Revista de Derecho Privado (Universidad Externado de Colombia), 21 (2011), pp. 8 ss.; Siles VAllejos, Abraham Santiago, La dictadura en la República romana clásica como referente paradigmático del régimen excepcional constitucional, en Derecho PUCP. Revista de la Facultad de Derecho, 73 (2014), pp. 411 ss; Pelloso, Carlo, La dittatura tra modelo romano,neoromano e italico, en Diritto@ Storia. Rivista Internazionale di Scienze Giuridiche e Tradiz̧ione Romana, 17 (2019), disponible en http://www.dirittoestoria.it/17/tradizione/PellosoDittatura-modello-romano-neo-romano-italico.htm. Se ha de poner, por su proximidad en el tiempo, la monografía de autoría colectiva bajo la dirección de GAROFALO, Luigi, La dittatura romana (Napoli, Jovene, 2017), I, pp. 516 ss., en la que se abordan con profundidad muchos de los aspectos de esta peculiar magistratura.

${ }^{20}$ Mediante este instrumento, el Senado, proclamando el iustitium (estado de excepción), confería poderes extraordinarios a los cónsules para salvaguardar la seguridad de la República ante la amenaza exterior o frente a gravísimas convulsiones internas (tumultus). La fórmula, recogida en las fuentes, que justifica la intensificación del poder consular era ne quid res publica detrimenti capiat, esto es, para que la República no sufra menoscabo. Cfr. Liv. 10, 21, 2: "bis nuntiis senatus conterritus iustitium indici, dilectum omnis generis hominum haberi iussit"; y Caes. B. C. 1, 5: "decurritur ad illud extremum atque ultimum senatus consultum, quo nisi paene in ipso urbis incendio atque in desperatione omnium salutis sceleratorum audacia numquam ante descensum est: dent operam consules, praetores, tribuni plebis, quique pro consulibus sint ad urbem, ne quid res publica detrimenti capiat'. Vid. también Ungern-STERnberg vON PÜRKel, Jürgen, Untersuchungen zum spätrepublikanischen Notstandrecht. Senatusconsultum ultimum und hostis-Erklärung (München, C. H. Beck'sche Verlagsbuchhandlung, 1970), pp. 55 ss.; AgAmBen, Giorgio, Stato di eccezione (Torino, Bollati Boringhieri, 2003), pp. 55 ss.; y CASTÁn PÉrez-Gómez, Santiago, Cicerón entre el fragor de las luchas políticas: el consulado del 63 a. C. y el debate en torno a la legalidad del senatus consultum ultimum, en Revista Internacional de Derecho Romano, 16 (2016), p. 308, n. 77.
} 
poder en una sola persona había sido siempre una necesidad en los momentos de emergencia pública: dum necesse erat resque ipsa cogebat, unus omnia poterat (pro Roscio, $48,139)$, pero el problema estaba en que aquel poder excepcional tendía por sí mismo a prorrogar el estado de excepción: nam cum otio langueremus, et is esset rei publicae status ut eam unius consilio atque cura gubernari necesse esset (de nat. deor. 1, 4, 7). Entre estos dos términos, la necesidad originaria y la perduración subsiguiente, está el problema político todo del estado de excepción" ${ }^{21}$. Su paralelismo con los estados de emergencia que prevé la Constitución Española ${ }^{22}$, desde el estado de alarma hasta el estado de sitio pasando por el estado de excepción ${ }^{23}$, resulta evidente y no desmerece el carácter democrático de un régimen que, en circunstancias excepcionales, se veía abocado a despojarse, no sin sujeción a ciertos controles, del funcionamiento ordinario de sus instituciones para poder hacer frente con mayor eficiencia a amenazas excepcionales ${ }^{24}$.

Muchos de los casos de epidemia narrados en las fuentes que motivaron el otorgamiento de poderes extraordinarios se asocian a la dictadura, por lo que en este trabajo me limitaré a referirme a esta institución ${ }^{25}$.

${ }^{21}$ D’Ors, Álvaro, Cicerón, sobre el estado de excepción, en Cuadernos de la Fundación Pastor, 3 (1961), p. 12.

${ }^{22}$ Y que están presentes en la regulación constitucional de todos los Estados democráticos, no sin dejar de mostrar las dificultades que hallan para, sin socavar las bases sobre las que se asientan, ofrecer mecanismos eficaces para combatir situaciones extraordinarias. Cfr. CARDILLI, Riccardo, cit. (n. 18), p. 29.

${ }^{23} \mathrm{El}$ art. 116.1 de la Constitución Española dispone que "una ley orgánica regulará los estados de alarma, de excepción y de sitio, y las competencias y limitaciones correspondientes". El gobierno de España, ante la crisis sanitaria desatada por el Covid-19, declaró el estado de alarma por real decreto 463/2020, de 14 de marzo, cuya persistencia, articulada a través de diferentes prórrogas ha de ajustarse, como previene el art. 116.2 de la Constitución Española ("el estado de alarma será declarado por el Gobierno mediante decreto acordado en Consejo de Ministros por un plazo máximo de quince días, dando cuenta al Congreso de los Diputados, reunido inmediatamente al efecto y sin cuya autorización no podrá ser prorrogado dicho plazo"), al contenido de la Ley Orgánica 4/1981, de 1 de junio, de los estados de alarma, excepción y sitio. La fórmula de la declaración del estado de alarma como la más adecuada se sustenta en el art. 4.b), que menciona específicamente como alteración grave de la normalidad las situaciones de crisis sanitaria, como las epidemias.

${ }^{24}$ También ocasionalmente la designación de un dictador venía acompañada de un iustitium. Cfr. Liv. 3, 27, 2-6: "cum magistro equitum in contionem venit, iustitium edicit, claudi tabernas tota urbe iubet, vetat quemquam privatae quicquam rei agere; tum quicumque aetate militari essent armati cum cibariis in dies quinque coctis vallisque duodenis ante solis occasum Martio in campo adessent; quibus aetas ad militandum gravior esset, vicino militi, dum is arma pararet vallumque peteret, cibaria coquere iussit. Sic iuventus discurrit ad vallum petendum. Sumpsere unde cuique proximum fuit; prohibitus nemo est; impigreque omnes ad edictum dictatoris praesto fuere"; y Liv. 7, 6, 12: "Ap. Claudium, quia dissuaserat legem, maiore nunc auctoritate eventum reprehensi ab se consilii incusantem, dictatorem consensu patriciorum Servilius consul dicit, dilectusque et iustitium indictum".

${ }^{25}$ Además del dictator clavi figendi causa, al que nos referiremos luego como conductor de un ritual religioso ordenado a aplacar la cólera divina manifestada en forma de epidemia, pueden mencionarse, entre otros, los designados reigerendae causa (Liv. 7, 3, 9 y 8, 29, 9) y belli gerendi causa (Liv. 8, 40, 2); comitiorum habendorum causa (Liv. 3, 20, 8; 7, 9, 3; y 7, 22, 10); feriarum constituendarum causa (Liv. 7, 28, 7); y comitiorum ludorumque faciendorum causa (Liv. 27, 33, 6). 


\section{LA DICTADURA COMO MAGISTRATURA EXTRAORDINARIA}

La dictadura suponía la intensificación del imperium ordinario de los cónsules, jefes políticos y militares de la República, atribuyendo las máximas prerrogativas a un personaje carismático denominado dictator, cuya aparición a comienzos del siglo $\mathrm{V}$ a. C. vino motivada por las tensiones políticas tanto internas como externas que amenazaban la estabilidad del orden republicano ${ }^{26}$. Aunque no faltan otras denominaciones (praetor maximus o magister populi), la semántica de este término en el contexto constitucional romano se aleja notablemente de la acepción moderna, no tanto en cuanto a la intensidad del $\operatorname{poder}^{27}$, que es y ha sido siempre máxima, sino en cuanto a la extensión temporal de ese poder extraordinario, limitado en el mundo romano a lo imprescindible (por principio, al plazo de seis meses $^{28}$, sin perjuicio de su cesación anticipada una vez cumplida

${ }^{26}$ Pomp. 1. sing. Enchir. D. 1, 2, 2, 18 se refiere en particular a las amenazas exteriores: "et his dictatoribus magistri equitum iniungebantur sic, quo modo regibus tribuni celerum: quod officium fere tale erat, quale hodie praefectorum praetorio, magistratus tamen habebantur legitimi". También lo hace Liv. 2, 18, 4-5: "in hac tantarum expectatione rerum sollicita civitate, dictatoris primum creandi mentio orta. Sed nec quibus consulibus quia ex factione Tarquiniana essent-id quoque enim traditor-parum creditum sit, nec quis primum dictator creatus sit, satis constat. Apud veterrimos tamen auctores T. Largium dictatorem primum, Sp. Cassium magistrum equitum creatos invenio". A las convulsiones internas se refiere Dion. Hal. 5, 70, 1, que llevó al Senado, para apaciguar el proceder revolucionario de la plebe, a introducir un instrumento constitucional que comportase la supresión temporal de las magistraturas ordinarias

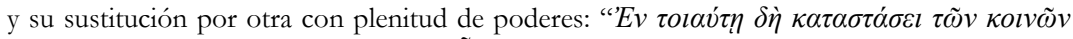

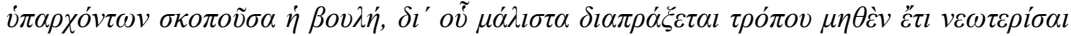

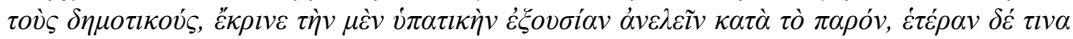

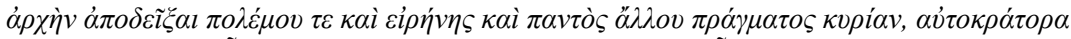

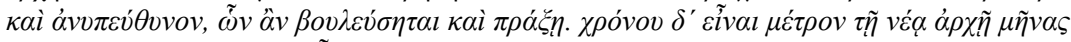

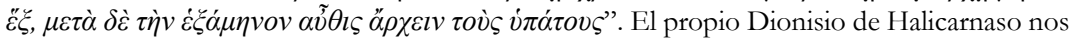

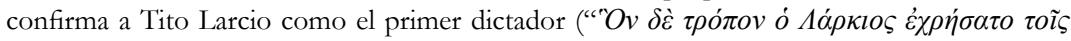

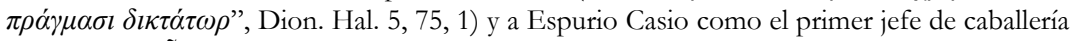

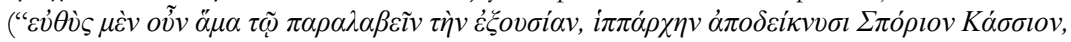

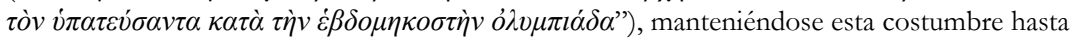

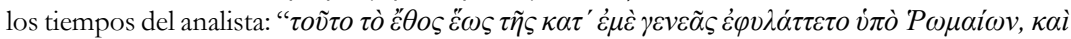

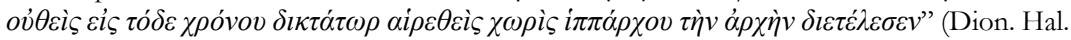
5, 75, 2). Así lo recoge también Pomp. 1. sing. Enchir. D. 1, 2, 2, 19: "et his dictatoribus magistri equitum iniungebantur sic, quo modo regibus tribuni celerum".

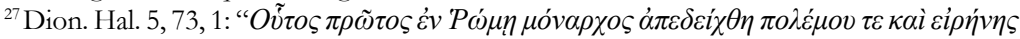

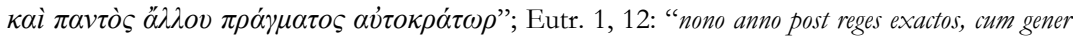
Tarquini ad iniuriam soceri vindicandam ingentem collegisset exercitum, nova Romae dignitas est creata, quae dictatura appellatur, maior quam consulatus"; y Oros. Hist. 2, 5, 4: "post haec Sabini conrasis undique copiis magno apparatu belli Romam contendunt. quo metu consternati Romani dictatorem creant, cuius auctoritas et potentia consulem praeiret; quae res in illo tunc bello plurimum emolumenti tulit'.

${ }^{28}$ Liv. 3, 29, 7: “dictatura in sex menses accepta”; Liv. 9, 34, 12: "quem semestri dictatura [...] putes?”; Liv. 23, 22, 11: "nocte proxima, ut mos erat, M. Fabium Buteonem ex senatus consulto sine magistro equitum dictatorem in sex menses dixit"; Liv. 23, 23, 2: "is [...] probare se dixit [...] nec dictatori, nisi rei gerendae causa creato, in sex menses datum imperium"; Cic. Leg. 3, 3, 9: "oenus ne amplius sex menses, si senatus creverit"; y Pomp., 1. sing. Enchir. D. 1, 2, 2, 18: "bunc magistratum, quoniam summam potestatem habebat, non erat fas ultra sextum mensem retineri". 
su misión ${ }^{29} \mathrm{o}$, en algún caso excepcional, su fáctica permanencia prorrogada ${ }^{30}$ ) para, con mayor margen de maniobra, superar la situación de extrema gravedad que aquejaba a la República ${ }^{31}$. La designación, tras la habilitación del Senado por senadoconsulto con el refrendo del pueblo ${ }^{32}$, competía a los propios cónsules ${ }^{33}$, incapaces en el ejercicio ordinario de su imperio de poner fin a la situación. De

${ }^{29}$ Incluso podía limitarse a unos pocos días. Así, Liv. 3, 29, 7: "Quinctius sexto decimo die dictatura in sex menses accepta se abdicavit"; Liv. 4, 47, 6: "dictator exercitu victore Romam reducto, die octavo quam creatus erat, magistratu se abdicavit"; Liv. 6, 29, 10: "die vicesimo quam creatus erat dictatura se abdicavit"; Liv. 9.18.13: "et quo sint mirabiliores quam Alexander aut quisquam rex, denos vicenosque dies quidam dictaturam, nemo plus quam annum consulatum gessit"; Liv. 9, 34, 12-13: "quem semestri dictatura, quem interregno quinque dierum contentum fore putes? Quem clavi figendi aut ludorum causa dictatorem audacter crees? Quam isti stolidos ac socordes videri creditis eos qui intra vicesimum diem ingentibus rebus gestis dictatura se abdicaverunt aut qui vitio creati abierunt magistratu"; Liv. 23, 23, 7: "ita centum septuaginta septem cum ingenti adprobatione bominum in senatum lectis, extemplo se magistratu abdicavit privatusque de rostris

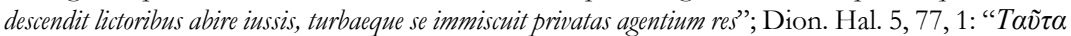

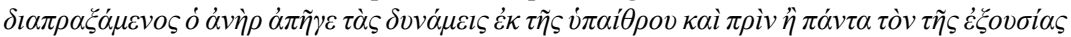

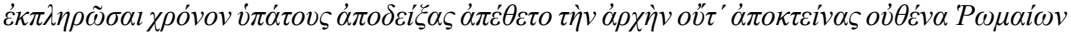

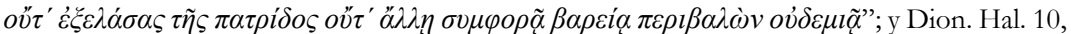

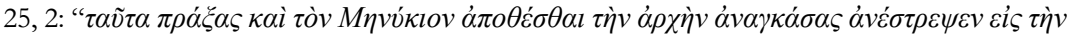

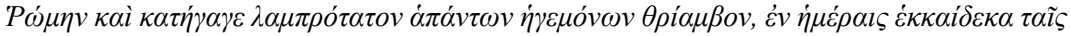

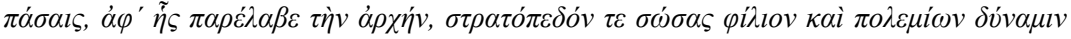

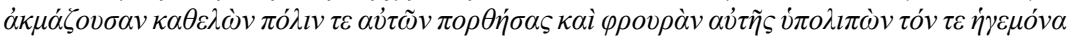

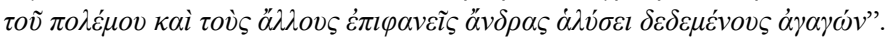

${ }^{30}$ Es el caso del dictador Camilo en el 390 a. C., según Liv. 6, 1, 4: “ceterum primo quo adminiculo erecta erat eodem innixa M. Furio principe stetit, neque eum abdicare se dictatura nisi anno circumacto passi sunt".

${ }^{31}$ Cic. Leg. 3, 3, 9: " 'Ast quando duellum gravius discordiaeve civium escunt, oenus ne amplius sex menses, si senatus creverit, idem iuris quod duo consules teneto, isque ave sinistra dictus populi magister esto. Equitatumque qui regat habeto pari iure cum eo quicumque erit iuris disceptator. Reliqui magistratus ne sunto"; Cic. Rep. 1, 40, 63: "gravioribus vero bellis es etiam sine collega omne imperium nostri penes singulos esse voluerunt, quorum ipsum nomen vim suae potestatis indicat. nam dictator quidem ab eo appellatur quia dicitur, sed in nostris libris vides eum Laeli magistrum populi appellari.' (Laelius) 'video' inquit. et Scipio: 'sapienter igitur illi vete<res>”; y 2, 32, 56: "atque his ipsis temporibus dictator etiam est institutus decem fere annis post primos consules, T. Larcius, novumque id genus imperii visum est et proximum similitudini regiae"; Varro, Ling. 5, 82: "dictator, quod a consule dicebatur, cui dicto audientes omnes essent. Magister equitum, quod summa potestas buius in equites et accensos, ut est summa populi dictator, a quo is quoque magister populi appellatus"; y 6.61: "binc dictator magister populi, quod is a consule debet dic"”; y Dion. Hal. $5,73,1$, que explica el origen del término, tanto por el poder de pronunciar edictos, como por la forma de ser elegido, no por el pueblo, sino por uno de los cónsules: “'ovo $\mu \alpha \delta$ ' $\alpha \dot{\tau} \tau \tilde{\omega}$

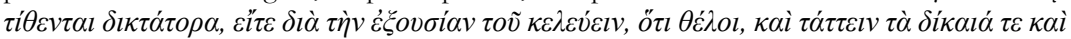

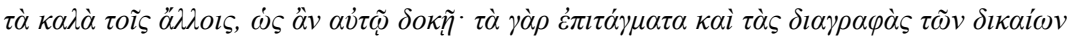

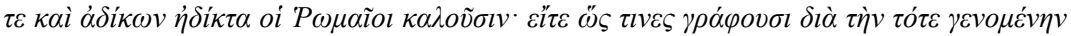

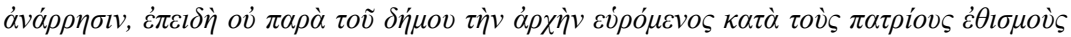

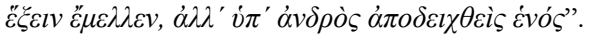

${ }^{32}$ Liv. 4, 17, 8: "et senatus, ut in trepidis rebus, dictatorem dici Mam. Aemilium iussit"; Liv. 4, 23, 5: "senatus Mam. Aemilium dictatorem iterum dici iussif"; Liv. 4, 26, 5: "senatui dictatorem dici placuit, quia etsi saepe victi populi maiore tamen conatu quam alias unquam rebellarant"; Liv. 4, 56, 8: "quae ubi tumultu maiore etiam quam res erat nuntiantur Romam, senatus extemplo, quod in rebus trepidis ultimum consilium 
esta foma, la previsión de un procedimiento para el nombramiento del dictator y la delimitación de las causas extraordinarias que lo justificaban contribuyen a robustecer la imagen de esta magistratura como propiamente constitucional, no tanto en el sentido eminentemente formal del derecho moderno en cuanto expediente jurídico perfectamente definido ex ante, sino en cuanto a su misma fundamentación en el consenso colectivo encarnado en la tradición. Puede así sostenerse la consideración de la dictadura como "magistratura pienamente coerente al sistema giuridico-religioso fondamentale del comune, il quale appunto, nel pieno rispetto del regime costituzionale fondato sul 'mos', permetteva di rispondere efficacementealle situaizoni di emergenza, senza che ciò però comportasse una sospensione delle ittituzioni repubblicane nella loro complessità (senato, comiži, altre magistrature, collegi sacerdotali)"34.

El recurso a esta magistratura extraordinaria comportó, al menos hasta alrededor del 325 a. C. ${ }^{35}$, la suspensión de la garantía constitucional por antonomasia:

erat, dictatorem dici iussit"; Liv. 5, 46, 10: "accepto inde senatus consulto uti comitiis curiatis revocatus de exsilio iussu populi Camillus dictator extemplo diceretur"; Liv. 6, 11, 10: "sed nova consilia Manli magis compulere senatum ad dictatorem creandum"; Liv. 6, 38, 3: "principio statim anni ad ultimam dimicationem de legibus ventum; et cum tribus vocarentur nec intercessio collegarum latoribus obstaret, trepidi patres ad duo ultima auxilia, summum imperium summumque ad civem decurrunt. Dictatorem dici placet; dicitur $M$. Furius Camillus, qui magistrum equitum L. Aemilium cooptat"; y Liv. 10, 11, 4: "consulis subrogandi comitia ex sententia principum habita: $M$. V alerium consulem omnes [sententiae] centuriae[que] dixere, ut patres ab iubendo dictatore deterruerint, quem senatus dictatorem dici iussurus fuerat'.

${ }^{33}$ Dion. Hal. 5, 71, 3 detalla profusamente el origen sobre el modo de designación por uno

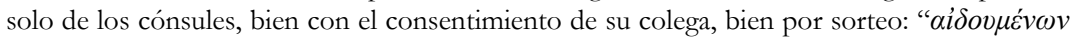

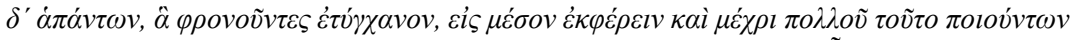

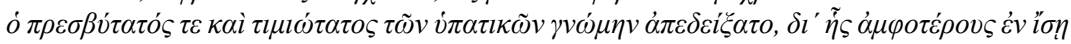

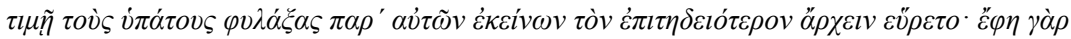

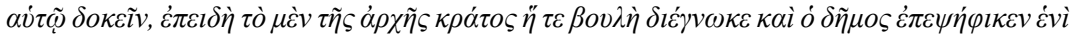

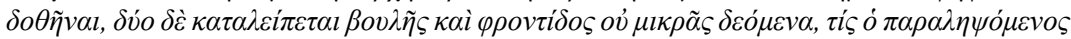

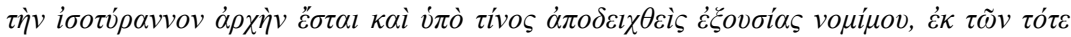

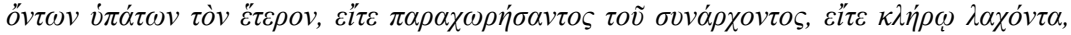

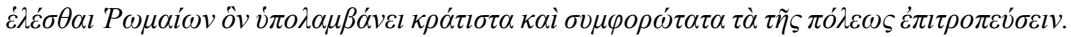

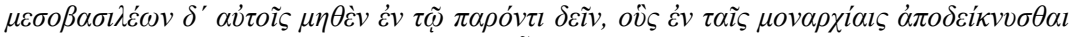

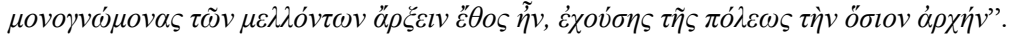

${ }^{34}$ Cardilli, Riccardo, cit. (n. 18), p. 38.

${ }^{35}$ Liv. 8, 30-35 nos da cuenta por entonces del incidente entre el dictador Lucio Papirio Cursor y su magister equitum Quinto Fabio Máximo Ruliano por la exitosa, pese a no ser favorables los auspicios, acción militar emprendida unilateralmente por éste contra los samnitas. Buscando refugio en el Senado frente a la cólera del dictador, deseoso de dar un ejemplarizante escarmiento a su subordinado, Marco Fabio, tres veces cónsul y dictador en otro tiempo, padre del magister equitum, reprochó al dictador el comportamiento tiránico que se disponía a emprender: "et patre auctore $M$. Fabio, qui ter iam consul dictatorque fuerat, vocato extemplo senatu, cum maxime conquereretur apud patres vim atque iniuriam dictatoris, repente strepitus ante curiam lictorum summoventium auditur et ipse infensus aderat, postquam comperitprofectum ex castris, cum expedito equitatu secutus. Iteratur deinde contentio et prendi Fabium Papirius iussit. Ubi cum deprecantibus primoribus patrum atque universo senatu perstaret in incepto immitis animus, tum pater M. Fabius 'quando quidem' inquit 'apud te nec auctoritas senatus nec aetas mea, cui orbitatem paras, nec virtus nobilitasque magistri equitum a te ipso nominati valet nec preces, quae saepe hostem mitigavere, quae deorum iras placant, tribunos plebis appello et pronoco ad populum eumque 
la provocatio ad populum ${ }^{36}$, esto es, la posibilidad de suspender la ejecución de las penas capitales acordadas por los magistrados cum imperio en el ejercicio de su potestad coercitiva en tanto no se pronunciase el pueblo romano convocado por el interesado al efecto para dar carta de naturaleza al denominado iudicium populi ${ }^{37}$.

tibi, fugienti exercitus tui, fugienti senatus indicium, indicem fero, qui certe unus plus quam tua dictatura potest polletque. Videro cessurusne provocationi sis, cui rex Romanus Tullus Hostilius cessit”' (Liv. 8, 33, 6-8). Este incidente marcó un antes y un después en la intensidad del imperium extraordinario de los dictadores, lo que indudablemente abocó a su decadencia.

${ }^{36}$ Apio Claudio, a través de Liv. 2, 29, 9-12, señalaba así las diferencias entre el poder de los cónsules y el del dictador: "id adeo malum ex provocatione natum; quippe minas esse consulum, non imperium, ubi ad eos qui una peccaverint provocare liceat. 'Agedum' inquit, 'dictatorem, a quo provocatio non est, creemus; iam bic quo nunc omnia ardent conticescet furor. Pulset tum mibi lictorem qui sciet ius de tergo vitaque sua penes unum illum esse cuius maiestatem violarit". Esta ausencia de sujeción de sus dictados a los límites de la provocatio se refleja también en Liv. 2, 18, 8: "creato dictatore primum Romae, postquam praeferri secures viderunt, magnus plebem metus incessit, ut intentiores essent ad dicto parendum; neque enim ut in consulibus qui pari potestate essent, alterius auxilium neque provocatio erat neque ullum usquam nisi in cura parendi auxilium"; Liv. 3, 20, 8: "terrebant haec; sed ille maximus terror animos agitabat, quod saepius Quinctius dictitabat se consulum comitia non habiturum; non ita civitatem aegram esse ut consuetis remediis sisti possit; dictatore opus esse rei publicae, ut, qui se moverit ad sollicitandum statum civitatis, sentiat

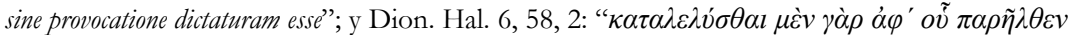

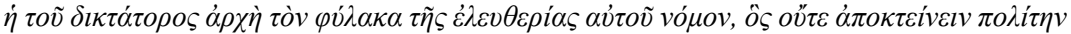

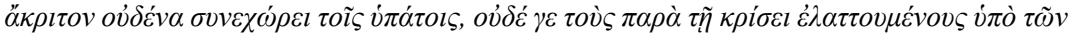

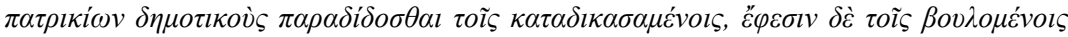

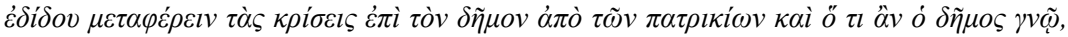

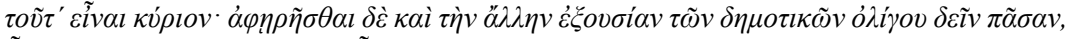

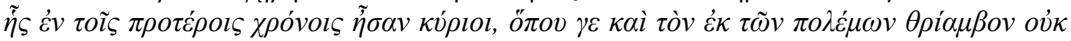

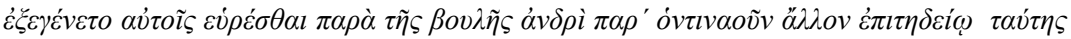

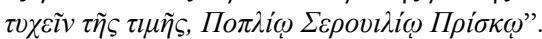

${ }^{37}$ De ahí el temor de la plebe tras la designación del primer dictador, según refiere Liv. 2, 18, 8: "creato dictatore primum Romae, postquam praeferri secures viderunt, magnus plebem metus incessit, ut intentiores essent ad dicto parendum; neque enim ut in consulibus qui pari potestate essent, alterius auxilium neque provocatio erat neque ullum usquam nisi in cura parendi auxilium". Sobre el sentido y alcance de la provocatio ad populum, son fundamentales los siguientes fragmentos: Cic. Leg. 3, 3, 6: " justa imperia sunto, isque cives modeste ac sine recusatione parento. Magistratus nec oboedientem et $<$ in $>$ noxium civem multa vinculis verberibusve coherceto, ni par maiorve potestas populusve probibessit, ad quos provocatio esto. Cum magistratus iudicassit inrogassitve, per populum multae poenae certatio esto. Militiae ab eo qui imperabit provocatio nec esto, quodque is qui bellum geret imperassit, ius ratumque esto"'; Cic. Rep. 2, 31, 53-54: "idemque, in quo fuit Publicola maxime, legem ad populum tulit eam quae centuriatis comitiis prima lata est, ne quis magistratus civem Romanum adversus provocationem necaret neve verberaret. Provocationem autem etiam a regibus fuisse declarant pontificii libri, significant nostri etiam angurales, itemque ab omni iudicio poenaque provocari licere indicant XII tabulae conpluribus legibus, et quod proditum memoriae est, X viros qui leges scripserint sine provocatione creatos, satis ostendit reliquos sine provocatione magistratus non fuisse, Lucique $V$ aleri Potiti et $M$. Horati Barbati, hominum concordiae causa sapienter popularium, consularis lex sanxit ne qui magistratus sine provocatione crearetur, neque vero leges Porciae, quae tres sunt trium Porciorum ut scitis, quicquam praeter sanctionem attulerunt novi"; Cic. de Orat. 2, 48, 199: "tum illa, quae modo Crassus commemorabat, egi: neque reges ex hac civitate exigi neque tribunos plebis creari neque plebiscitis totiens consularem potestatem minui neque provocationem, patronam illam civitatis ac vindicem libertatis, populo Romano dari sine nobilium dissensione potuisse"; Cic. Leg. Agr. 2, 13, 33: "perspicite quanta potestas permittatur; non privatorum insaniam, sed intolerantiam regum esse dicetis. Primum permittitur infinita potestas innumerabilis pecuniae conficiendae vestris vectigalibus non fruendis, sed alienandis; deinde orbis terrarum gentiumque omnium 
La sujeción del dictador a los límites de la provocatio comportó paulatinamente su desaparición, como podrían evidenciar las pocas ocasiones en que se recurrió a la dictadura en el curso de los siglos IV y III a. C. ${ }^{38}$, coincidiendo, bien es cierto, con el período de mayor firmeza y estabilidad del armazón republicano. Emergió, sin embargo, nuevamente, asociada a los míticos personajes del epílogo de la República romana, como Sila (82 a 79 a. C.) ${ }^{39}$ y César $(49 \text { a } 44 \text { a. C. })^{40}$, siendo formalmente abolida tras la muerte del conquistador de las Galias ${ }^{41}$.

datur cognitio sine consilio, poena sine provocatione, animadversio sine auxilio"; Liv. 3, 56, 13: "se documento futurum utrum novis legibus dominatio an libertas firmata sit, et appellatio provocatioque adversus iniuriam magistratuum ostentata tantum inanibus litteris an vere data sit"; Sen. Epist. 108, 31: "provocationem ad populum etiam a regibus fuisse"; Flor. Epit. 1, 9, 4: "nam et fasces ei pro contione submisit, et ius provocationis adversus ipsos dedit, et ne specie arcis offenderet, eminentis aedis suas in plana submisit"; Val. Max. 4, 1, 1: "legem etiam comitiis centuriatis tulit, ne quis magistratus civem Romanum adversus provocationem verberare aut necare vellet"; y Pomp. 1. sing. Enchir. D. 1, 2, 2, 16: "qui [consules] tamen ne per omnia regiam potestatem sibi vindicarent, lege lata factum est, ut ab eis provocatio esset neve possent in caput civis Romani animadvertere iniussu populi".

${ }^{38}$ Los últimos dictadores a la usanza tradicional recogidos en los fasti capitolini fueron M. Iunius D. f. D. n. Pera (216 a. C.) como rei gerundae causa y C. Servilius C. f. P. nepos (202 a. C.) como comitiorum habendorum causa. Cfr. Degrassi, Attilio, Fasti Capitolini (Torino, G. B. Paravia \& C., 1954), pp. 60 y 62. Kaplan, Arthur, Religious Dictators of the Roman Republic, en The Classical World, 67/3 (1973-1974), p. 172 contabiliza 85 dictadores entre el 501 y el 202 a. C.

${ }^{39}$ Degrassi, Attilio, cit. (n. 38), pp. 74 s. Sila recibió de la mano de Lucio Valerio Flaco, a la sazón interrex en el 82 a. C., la atribución de dictator rei publicae constituendae, quedando el proponente como magister equitum. He aquí la valoración en Cic. Leg. 1, 42 de aquella disposición: "nibilo credo magis illa quam interrex noster tulit, ut dictator quem uellet ciuium <nominatim > aut indicta causa inpune posset occidere". Vid. también, a propósito de tan irregular nombramiento, Cic. Att. 9, 15: "etsi, si Sulla potuit efficere ab interrege ut dictator diceretur [et magister equitum], cur hic non possit?"; Cic. Leg. Agr. 3, 5: "omnium legum iniquissimam dissimillimamque legis esse arbitror eam quam L. Flaccus interrex de Sulla tulit, ut omnia quaecumque ille fecisset essent rata. Nam cum ceteris in civitatibus tyrannis institutis leges omnes exstinguantur atque tollantur, bic rei publicae tyrannum lege constituit. Est invidiosa lex, sicuti dixi, verum tamen habet excusationem; non enim videtur hominis lex esse, sed temporis"; y Plut.

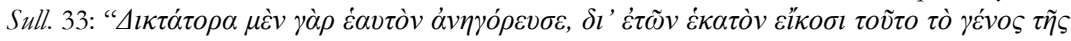

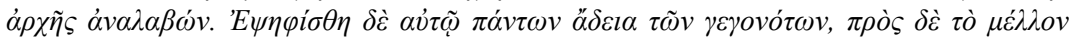

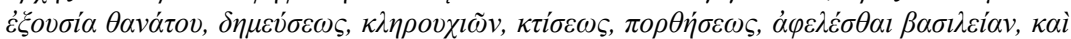

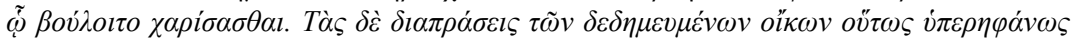

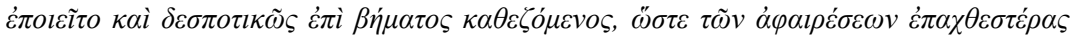

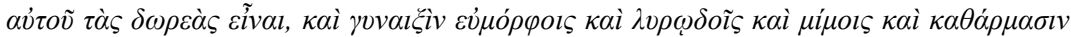

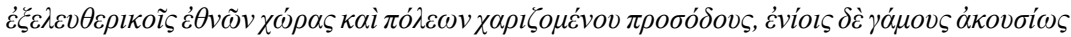
$\zeta \varepsilon v \gamma v v \mu \varepsilon \dot{v} \omega v$ $v v \alpha \iota \kappa \tilde{\omega} v^{\prime \prime}$.

${ }^{40}$ Degrassi, Attilio, cit. (n. 38), pp. 76 ss. Caes. B.C. 2, 21: "ibi legem de dictatore latam seseque

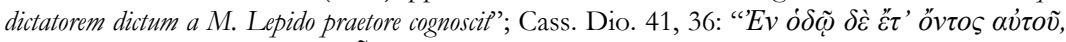

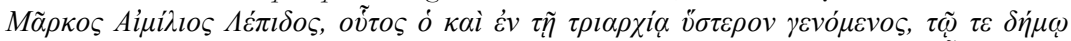

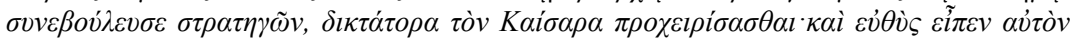

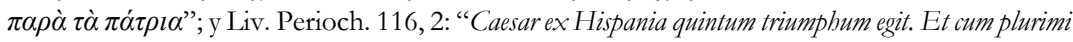
maximique honores a senatu decreti essent, inter quos ut 'parens patriae' appellaretur et sacrosanctus ac dictator in perpetuum esset, inuidiae aduersus eum causam praestiterunt, quod senatui deferenti hos honores, cum ante aedem Veneris Genetricis sederet, non adsurrexit, et quod a $M$. Antonio cos., collega suo, inter lupercos currente diadema capiti suo impositum in sella reposuit, et quod Epidio Marullo et Caesetio Flauo trib. pl., innidiam ei tamquam regnum adfectanti mouentibus potestas abrogata est'.

${ }^{41}$ Dion. Hal. 5, 77, 4 identifica a Sila como responsable de la perversión de la dictadura 


\section{LA ADOPCIÓN DE MEDIDAS EXTRAORDINARIAS POR CAUSA DE EPIDEMIA}

\section{Las epidemias en la historiografía del período republicano}

Interesa en particular, por su evidente relación con la declaración del estado de alarma por razones sanitarias, traer a colación algunos casos semejantes contemplados en las fuentes romanas. Como ya hemos apuntado, el nombramiento de un dictador en los primeros siglos de la República romana podía darse clavi figendi causa (por causa de la inserción de un clavo), esto es, para que bajo su comando se procediese a insertar un clavo en los muros del templo de Júpiter Óptimo Máximo como forma de recabar la intercesión divina frente al azote de la peste. $\mathrm{Y}$ es que los analistas de la historia romana, con Livio y Dionisio de Halicarnaso a la cabeza, refieren varios casos de epidemias en Roma. Así, Dionisio de Halicarnaso trae a colación un episodio de peste ya en tiempos de Rómulo, que animó el afán conquistador de los camerinos, convencidos de la vulneralibilidad de los

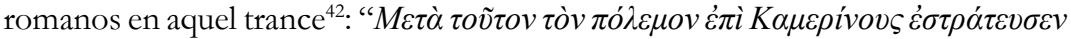

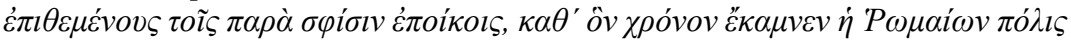

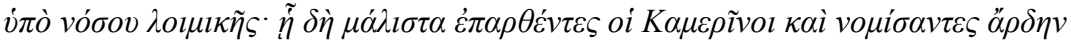

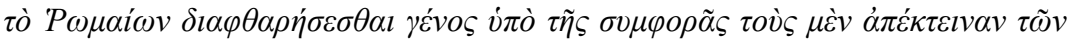

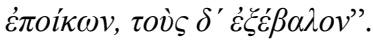

El propio Dionisio de Halicarnaso, en el contexto de la narración del suicidio de Lucrecia y del derrocamiento de Tarquinio el Soberbio, nos informa de una visita de sus hijos al oráculo de Delfos para buscar remedio frente a una epidemia que azotó especialmente a las jóvenes encintas, cayendo irremediablemente en

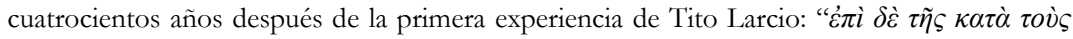

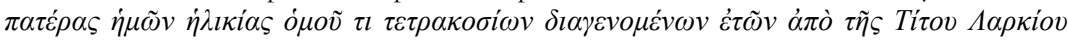

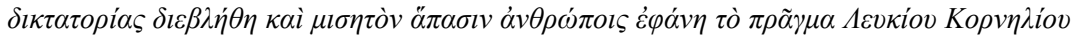

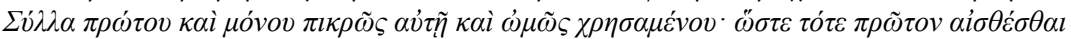

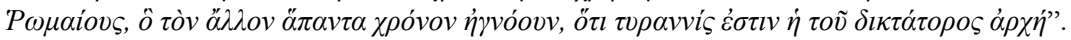
A su derogación formal por parte de Marco Antonio se refiere Cic. Phil. 1, 3: "dictaturam, quae iam vim regiae potestatis obsederat, funditus ex re publica sustulit"; 1, 4: "Iux quaedam videbatur oblata non modo regno, quod pertuleramus, sed etiam regni timore sublato, magnumque pignus ab eo rei publicae datum, se liberam civitatem esse velle, cum dictatoris nomen, quod saepe iustum fuisset, propterperpetuae dictaturae recentem memoriam funditus ex re publica sustulisset"; 1, 32: "proximo, altero, tertio, denique reliquis consecutis diebus, non intermittebas quasi donum aliquod cotidie afferre rei publicae, maximum autem illud, quod dictaturae nomen sustulisti. Haec inusta est a te, a te, inquam, mortuo Caesari nota ad ignominiam sempiternam. Ut enim propter unius M. Manli scelus decreto gentis Manliae neminem patricium Manlium Marcum vocari licet, sic tu propter unius dictatoris odium nomen dictatoris funditus sustulisti"; 2, 115: "recordare igitur illum, M. Antoni, diem, quo dictaturam sustulisti”; y 5, 10: "quibus de causis eas leges, quas M. Antonius tulisse dicitur, omnes censeo per vim et contra auspicia latas iisque legibus populum non teneri. Si quam legem de actis Caesaris confirmandis deve dictatura in perpetuum tollenda deve coloniis in agros deducendis tulisse $M$. Antonius dicitur, easdem leges de integro, ut populum teneant, salvis auspiciis ferri placet. Quamvis enim res bonas vitiose per vimque tulerit, tamen eae leges non sunt habendae, omnisque audacia gladiatoris amentis auctoritate nostra repudianda est";

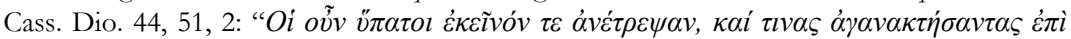

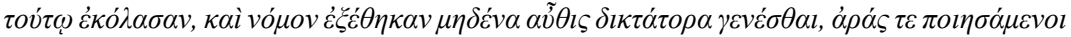

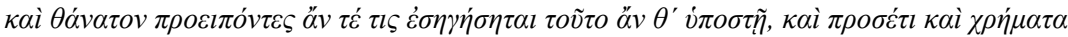

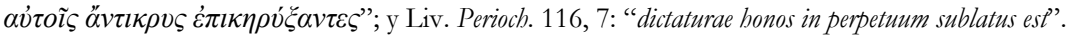

${ }^{42}$ Dion. Hal. 2, 54, 1. 


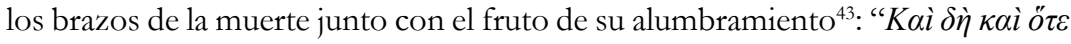

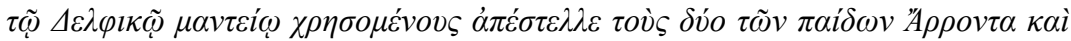

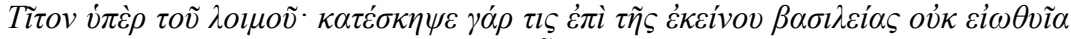

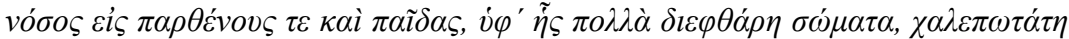

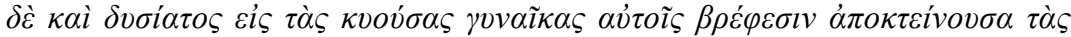

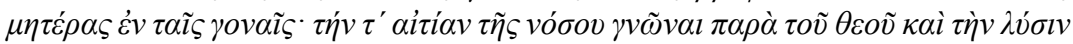

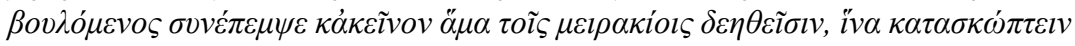

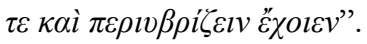

Todavía para la época monárquica, Livio señala como causa última de la muerte del rey Tulo Hostilio una epidemia, que había llegado a despertar en él una sobrevenida inquietud por la práctica religiosa, que trasladó al pueblo por no vislumbrar otro modo de congraciarse con los dioses, aunque, según el testimonio del analista, con infructuoso resultado al no prodigarse con la ortodoxia trazada por su predecesor Numa en la conducción del ritual expiatorio"4: " band ita multo post pestilentia laboratum est. Unde cum pigritia militandi oreretur, nulla tamen ab armis quies dabatur a bellicoso rege, salubriora etiam credente militiae quam domi iuvenum corpora esse, donec ipse quoque longinquo morbo est implicitus. Tunc adeo fracti simul cum corpore sunt spiritus illi feroces ut qui nibil ante ratus esset minus regium quam sacris dedere animum, repente omnibus magnis parvisque superstitionibus obnoxius degeret religionibusque etiam populum impleret. Volgo iam homines eum statum rerum qui sub Numa rege fuerat requirentes, unam opem aegris corporibus relictam si pax veniaque ab dis impetrata esset credebant. Ipsum regem tradunt volventem commentarios Numae, cum ibi quaedam occulta sollemnia sacrificia Iovi Elicio facta invenisset, operatum his sacris se abdidisse; sed non rite initum aut curatum id sacrum esse, nec solum nullam ei oblatam caelestium speciem sed ira Iovis sollicitati prava religione fulmine ictum cum domo conflagrasse. Tullus magna gloria belli regnavit annos duos et triginta".

En el 492 a. C., apenas estrenada la República y bajo el consulado de Tito Geganio y Publio Minucio ${ }^{45}$, según el testimonio de Livio $^{46}$ y Dionisio ${ }^{47}$, una peste terrible que por entonces sufrieron los volscos, dejando vivos en la populosa ciudad de Velitras, sin consideración a su edad o fortuna, uno de cada diez de sus habitantes, libró a los romanos de una situación crítica para la defensa de la ciudad por causa de la hambruna, que tuvo por causa la incultura de los campos con ocasión de las revueltas plebeyas y que obligó a los cónsules a promover expediciones bien lejanas para adquirir grano con el qe abastecer a la plebe, tal era el bloqueo que los romanos sufrían de parte de las ciudades vecinas: "eo anno cum et foris quieta omnia a bello essent et domi sanata discordia, aliud multo gravius malum civitatem invasit, caritas primum annonae ex incultis per secessionem plebis agris, fames deinde,

\footnotetext{
${ }^{43}$ Dion. Hal. 4, 69, 2.

${ }^{44}$ Liv. 1, 31, 5, 8.

${ }^{45}$ Degrassi, Attilio, cit. (n. 38), p. 150.

${ }^{46}$ Liv. 2, 34, 2.

${ }^{47}$ Dion. Hal. 7, 12, 3-5.
} 
qualis clausis solet [...] Incommodo bello in tam artis commeatibus vexati forent, ni Volscos iam moventes arma pestilentia ingens invasisset".

Para el 490 a. C., Dionisio ${ }^{48}$ nos da cuenta de la peste sufrida por Roma en el consulado de Sulpicio Camerino y Larcio Rufo ${ }^{49}$, que, sin embargo, no produjo demasiada mortandad entre los humanos. El analista se hace eco de las distintas corrientes populares, unas que veían en toda epidemia una manifestación del enojo de los dioses ante lo que Livio juzga como injusta condena al exilio de

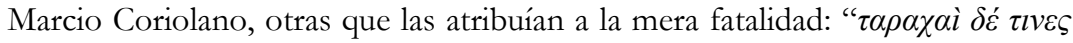

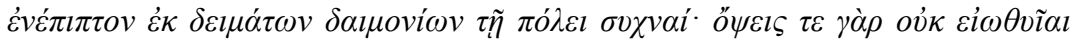

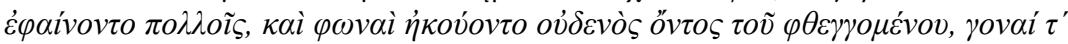

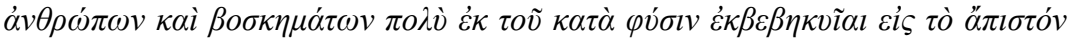

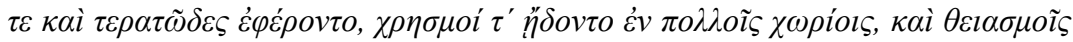

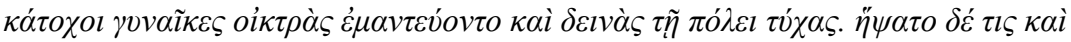

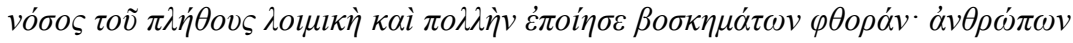

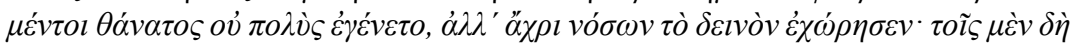

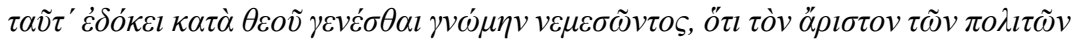

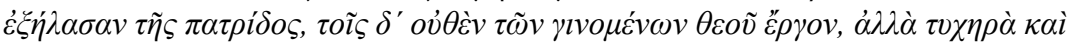

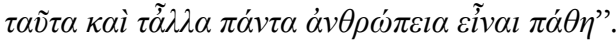

Para el 472 a. C., Dionisio relata los estragos de una epidemia que afectó especialmente a las mujeres encintas, sin que a tanta devastación pusiesen fin los rituales sacrificiales y súplicas de desagravio emprendidos. Desconcertada la ciudad, la delación de un esclavo a propósito de la pérdida de la virginidad de Urbinia, una de las vestales, comportó su relevo de la actividad religiosa y su sometimiento a juicio, siendo ella condenada conforme a los usos ${ }^{50}$, lo que prodigiosamente trajo consigo

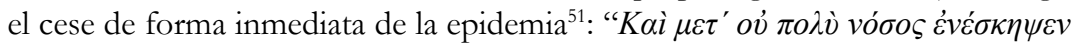

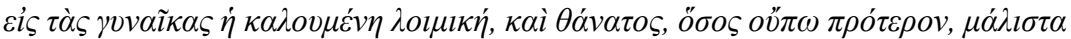
$\delta^{\prime} \varepsilon i \varsigma \tau \grave{\alpha} \varsigma \dot{\varepsilon} \gamma \kappa v ́ \mu o v \alpha \varsigma$.

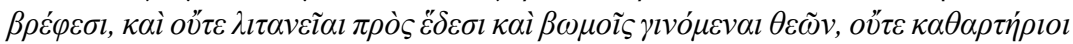

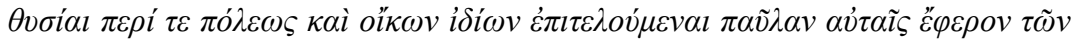

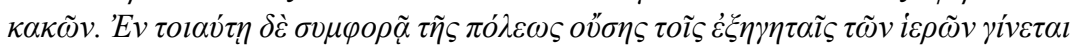

${ }^{48}$ Dion. Hal. 7, 68, 2.

${ }^{49}$ Degrassi, Attilio, cit. (n. 38), p. 151.

${ }^{50}$ En cuanto responsable de un crimen incesti por quebranto del voto de castidad que amenazaba con alterar la pax deorum, se le fustigaba, se le vestía con ropas fúnebres y era conducida en una litera cerrada al Campus sceleratum, junto a la Porta Collina, donde era enterrada viva provista de luz, pan, agua, leche y aceite, mientras que el que la había seducido era fustigado hasta la muerte. Vid. Lovisi, Claire, Vestale, incestus et juridiction pontificale sous la République romaine, en Mélanges de l'Ecole française de Rome. Antiquité, 110/2 (1998), pp. 699-735; MEKACHER, Nina, VAN Haeperen, Françoise, Le choix des Vestales, miroir d'une société en évolution (IIlème s. a. C. - Ier s. p. C.), en Revue de l'histoire des religions, 220/1 (2003), p. 64; SCARDigli, Barbara, Vestali integrate nella società romana, en Studia Historica. Historia Antigua, 21 (2003), p. 98; Kroppenberg, Inge, Law, Religion and Constitution of the Vestal Virgins, en Law \& Literature, 22/3 (2010), pp. 418-439; y Mattiangeli, Daniele, Il ruolo e privilegi delle vestali tra diritto, società, politica e religione. Un esempio unico all'interno dell'ordinamento giuridico romano, en Revista General de Derecho Romano, 19 (2012), pp. 8 y 16.

${ }^{51}$ Dion. Hal. 9, 40. 


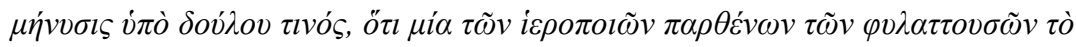

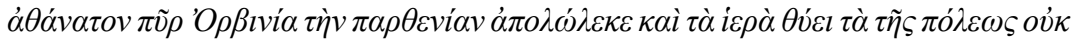

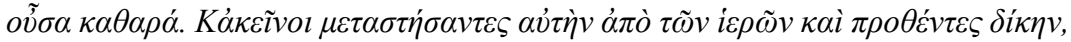

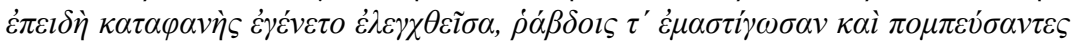

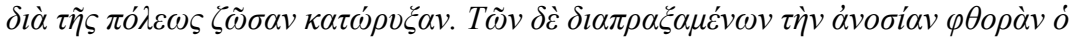

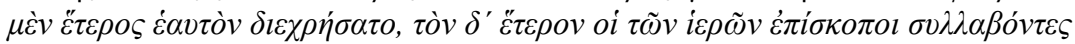

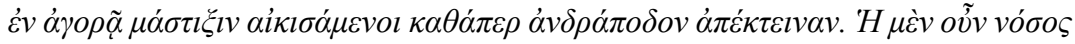

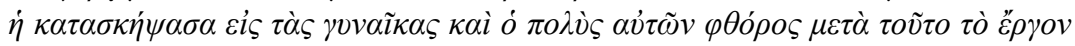
$\varepsilon \dot{v} \theta \dot{\jmath} \varsigma \dot{\varepsilon} \pi \alpha \dot{\sigma} \sigma \alpha \tau o^{\prime \prime 52}$.

En el 463 a. C., siendo cónsules Publio Servilio Prisco y Lucio Ebucio Hel$\mathrm{va}^{53}$, Roma, asolada por la peste, no pudo de entrada dispensar protección a sus aliados los hérnicos, cuyo territorio estaba siendo asediado por volscos y ecuos, hasta que al año siguiente remitió la epidemia. Así nos lo transmite Livio 54 : "grave tempus et forte annus pestilens erat urbi agrisque, nec hominibus magis quam pecori, et auxere vim morbi terrore populationis pecoribus agrestibusque in urbem acceptis. Ea conluvio mixtorum omnis generis animantium et odore insolito urbanos et agrestem confertum in arta tecta aestu ac vigiliis angebat, ministeriaque in vicem ac contagio ipsa volgabant morbos. Vix instantes sustinentibus clades repente legati Hernici nuntiant in agro suo Aequos Volscosque coniunctis copiis castra posuisse, inde exercitu ingenti fines suos depopulari. Praeterquam quod infrequens senatus indicio erat sociis adflictam civitatem pestilentia esse, maestum etiam responsum tulere, utper se ipsi Hernici cum Latinis res suas tutarentur; urbem Romanam subita deum ira morbo populari; si qua eius mali quies veniat, ut anno ante, ut semper alias, sociis opem laturos".

En el 453 a. C., con Sexto Quintilio y Publio Curiacio como cónsules ${ }^{55}$ y a las puertas de la génesis del texto decenviral (pues se estaba a la espera del regreso de la legación enviada a Atenas), Roma volvió a sufrir los perniciosos efectos de una epidemia en muchas de sus más significativas personalidades, acompañada también de dantescas consecuencias económicas por quedar el ganado diezmado. La noticia nos la manda Livio ${ }^{56}$ : "ab externis bellis quietus annus fuit, quietior insequens $P$. Curiatio et Sex. Quinctilio consulibus, perpetuo silentio tribunorum, quod primo legatorum qui Athenas ierant legumque peregrinarum exspectatio praebuit, dein duo simul mala ingentia exorta, fames pestilentiaque, foeda homini, foeda pecori. Vastati agri sunt, urbs adsiduis exhausta funeribus; multae et clarae lugubres domus. Flamen Quirinalis Ser. Cornelius mortuus, angur C. Horatius Pulvillus, in cuius locum C. Veturium, eo cupidius quia damnatus a plebe erat, angures legere. Mortuus consul Quinctilius, quattuor tribuni plebi. Multiplici clade foedatus annus; ab hoste otium fuit'.

Es muy posible que, a esta misma epidemia, con ligeras variaciones cronológicas, se refiriera Dionisio de Halicarnaso ${ }^{57}$. Con mayor lujo de detalles, el

\footnotetext{
${ }^{52} \mathrm{La}$ autenticidad del episodio, ausente en el relato liviano, es serveramente cuestionada por MünZER, Friedrich, Die römischen Vestalinnen bis zur Kaiserzeit, en Philologus, 92 (1937), pp. 213 s.

${ }^{53}$ Degrassi, Attilio, cit. (n. 38), p. 152.

${ }^{54}$ Liv. 3, 6, 2-6 (cfr. Dion. Hal. 9, 67).

${ }^{55}$ Degrassi, Attilio, cit. (n. 38), p. 152.

${ }^{56}$ Liv. 3, 32, 1-4.

${ }^{57}$ Dion. Hal. 10, 53, 1-6, con diferencias en la nomina consularia de Liv. 3, 32, 1-4, que men-
} 
analista da cuenta de cómo provocó la muerte de casi todos los esclavos y de aproximadamente la mitad de los ciudadanos romanos. La desgracia se extendió por tiempo de un año y su rápida propagación, que condujo a la desaparición de familias enteras, se vio favorecida por no dar a los cadáveres infectos su recurrente destino, corrompiendo, tanto en la ciudad como en el campo, el agua potable y el aire respirable, sin que los sacrificios y ritos expiatorios practicados, por no ser conformes con la ortodoxia tradicional, lograran aplacar sus perni-

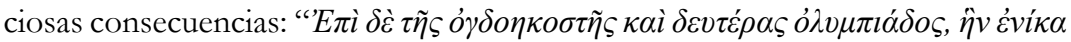

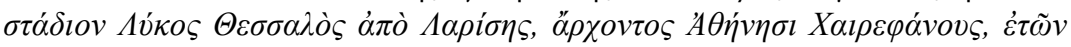

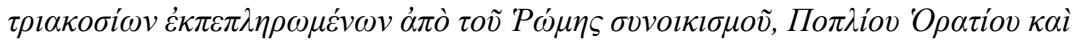

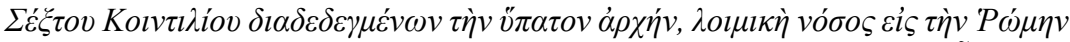

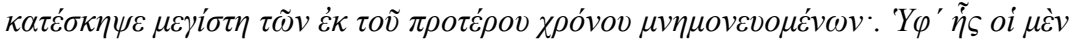

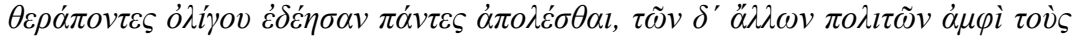

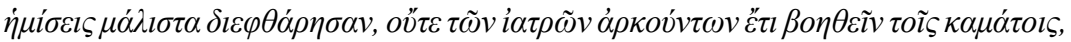

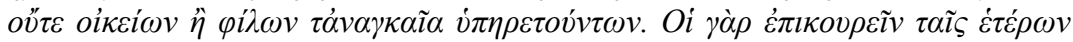

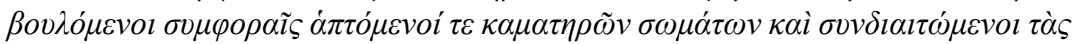

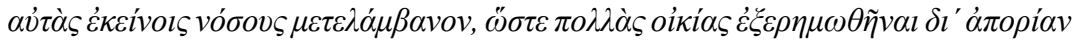

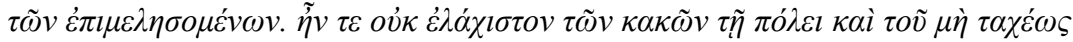

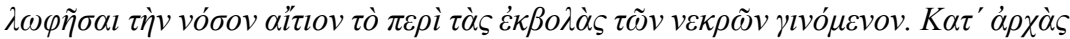

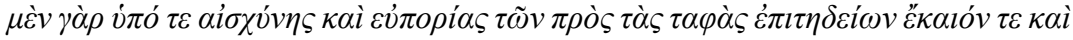

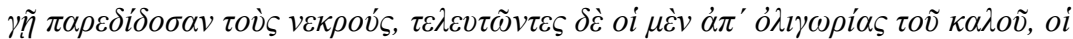

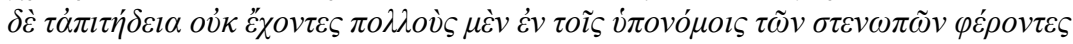

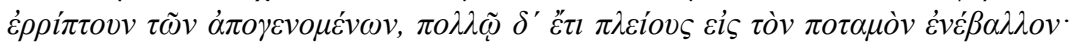

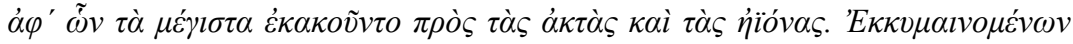

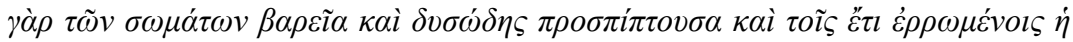

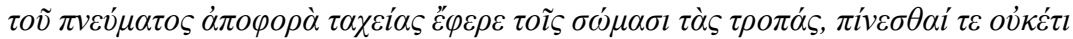

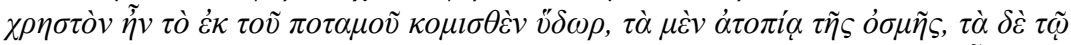

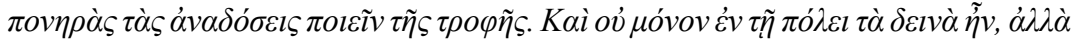

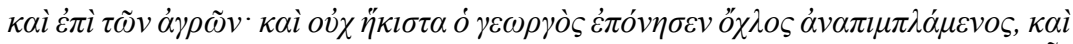

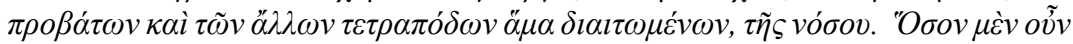

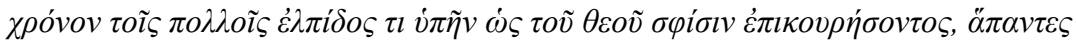

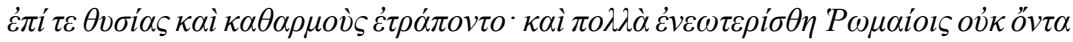

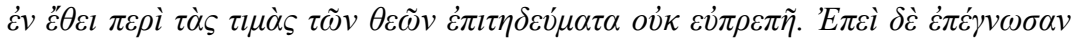

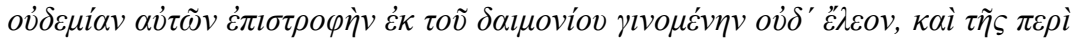

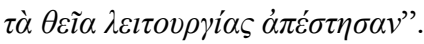

En el año 436 y, particularmente, en el 435 a. C., con Gayo Julio y Lucio Virginio como cónsules ${ }^{58}$, asoló Roma una epidemia que dejó expuesta la ciudad a los atrevidos saqueos de las vecinas ciudades de Fidenas y Veyes. La gravedad de la amenaza motivó que, con el consentimiento de ambos cónsules, se designara como dictator rei gerundae causa a Quinto Servilio ${ }^{59}$, el cual, con los mermados

ciona como acompañante de Sexto Quintilio a Publio Curiacio en lugar de a Publio Horacio, señalado por Dionisio. En Degrassi, Attilio, cit. (n. 38), p. 152 se identifica para el 451 a. C. como cónsules a Apio Claudio Craso y a Tito Genucio Augurino.

${ }^{58}$ Degrassi, Attilio, cit. (n. 38), p. 153.

${ }^{59}$ Ibíd., p. 181. 
efectivos disponibles por entonces, no sólo logró repeler la amenaza, sino que, con extraordinaria astucia, se las ingenió con maniobras de distracción para tomar al improviso y a través de una galería excavada la ciudad de Fidenas en la que los estruscos, debidamente aprovisionados, se habían hecho fuertes ${ }^{60}:$ " [...] urbes tamen non oppugnatae quia pestilentia populum invasit [...] Pestilentior inde annus C. Iulio iterum et L. Verginio consulibus tantum metus et vastitatis in urbe agrisque fecit, ut non modo praedandi causa quisquam ex agro Romano exiret belliue inferendi memoria patribus aut plebi esset, sed ultro Fidenates, qui se primo aut montibus aut muris tenuerant, populabundi descenderent in agrum Romanum. Deinde Veientium exercitu accito -nam Falisci perpelli ad instaurandum bellum neque clade Romanorum neque sociorum precibus potuere- duo populi transiere Anienem atque haud procul Collina porta signa habuere. Trepidatum itaque non in agris magis quam in urbe est. Iulius consul in aggere murisque explicat copias, a verginio senatus in aede Quirini consulitur. Dictatorem dici Q. Servilium placet, cui Prisco alii, alii Structo fuisse cognomen tradunt. Verginius dum collegam consuleret moratus, permittente eo nocte dictatorem dixit; is sibi magistrum equitum Postumum Aebutium Heluam dicit. Dictator omnes luce prima extra portam Collinam adesse iubet. Quibuscumque vires suppetebant ad arma ferenda praesto fuere. Signa ex aerario prompta feruntur ad dictatorem. Quae cum agerentur, hostes in loca altiora concessere. Eo dictator agmine infesto subit; nec procul Nomento signis conlatis fudit Etruscas legiones. Compulit inde in urbem Fidenas valloque circumdedit [...]".

No pasa por alto Livio las consecuencias económicas de las epidemias. Refiere así cómo, en el año 433 a. C., otra epidemia, que afectó de forma masiva a hombres y animales, provocó graves pérdidas en la ciudad y en el campo, trayendo consigo hambre, que sólo pudo aplacarse enviando a la búsqueda de trigo a Etruria, Cumas e incluso Sicilia. Nada pudo hacer la escrupulosa observancia del ritual conservado en los libros sibilinos para librar al pueblo romano de semejante devastación ${ }^{61}$ : "[...] Pestilentia eo anno aliarum rerum otium praebuit. Aedis Apollini pro valetudine populi vota est. Multa duumviri ex libris placandae deum irae avertendaeque a populo pestis causa fecere; magna tamen clades in urbe agrisque promiscua hominum pecorumque pernicie accepta. Famem quoque ex pestilentia morbo implicitis cultoribus agrorum timentes in Etruriam Pomptinumque agrum et Cumas, postremo in Siciliam quoque frumenti causa misere [...]".

En el año 428 a. C., una nueva epidemia hizo acto de presencia en la ciudad durante el mandato de los cónsules Aulo Cornelio Coso y Tito Quincio Peno ${ }^{62}$. Su origen último ha de hallarse en la galopante sequía, que provocó un ambiente insalubre por el amontonamiento de animales muertos, extendiéndose así el mal al conjunto de la población, comenzando por los más vulnerables (esclavos y campesinos), que, por pura desesperación, se entregaba a prácticas religiosas extranjeras hasta que tal proceder fue refrenado por los ediles ${ }^{63}$ : "siccitate eo anno plurimum laboratum est, nec caelestes modo defuerunt aquae, sed terra quoque ingenito umore egens vix ad perennes suffecit amnes. Defectus alibi aquarum circa torridos fontes rivosque

\footnotetext{
${ }^{60}$ Liv. 4, 21-22.

${ }^{61}$ Liv. 4, 25, 3-5.

${ }^{62}$ Degrassi, Attilio, cit. (n. 38), p. 154.

${ }^{63}$ Liv. 4, 30, 7-11.
} 
stragem siti pecorum morientum dedit; scabie alia absumpta, volgatique in homines morbi. Et primo in agrestes ingruerant servitiaque; urbs deinde impletur. Nec corpora modo adfecta tabo, sed animos quoque multiplex religio et pleraque externa invasit, novos ritus sacrificandi vaticinando inferentibus in domos quibus quaestui sunt capti superstitione animi, donec publicus iam pudor ad primores civitatis pervenit, cernentes in omnibus vicis sacellisque peregrina atque insolita piacula pacis deum exposcendae. Datum inde negotium aedilibus, ut animadverterent ne qui nisi Romani di neu quo alio more quam patrio colerentur".

La propagación de una epidemia imponía en no pocas ocasiones un cambio en el panorama político, invirtiéndose así el orden de las preocupaciones de los ciudadanos. Así, en el año 412 a. C., una epidemia comportó el confinamiento del pueblo en el hogar a fin de salvaguardar la propia salud, dejando así interrumpido, no sólo el cultivo de los campos, con el consiguiente temor a la subsiguiente hambruna, sino también la acción y el enfrentamiento político ${ }^{64}$, que sólo se retomó en todo su fragor apenas superada la coyuntura ${ }^{65}$ : "is cum principio statim anni, velut pensum nominis familiaeque, seditiones agrariis legibus promulgandis cieret, pestilentia coorta, minacior tamen quam perniciosior, cogitationes hominum a foro certaminibusque publicis ad domum curamque corporum nutriendorum avertit; minusque eam damnosam fuisse quam seditio futura fuerit credunt. Defuncta civitate plurimorum morbis, perpaucis funeribus, pestilentem annum inopia frugum, neglecto cultu agrorum, ut plerumque fit, excepit, M. Papirio Atratino C. Nautio Rutulo consulibus".

En el 392 a. C., ejerciendo el consulado Lucio Valerio Potito y Marco Manlio Capitolino $^{66}$, la epidemia diezmó el ejército romano, lo que despertó la arrogancia de volsinienses y sapinates. Al caer enfermos los cónsules, se procedió a la designación de seis tribunos militares con poderes consulares para conducir la campaña. Del episodio nos dan cuenta Livio ${ }^{67}$ y Dionisio, deteniéndose este último en la crudeza de la epidemia, especialmente en lo concerniente a los padecimientos cutáneos con los que se manifestaba: pequeñas erupciones al comienzo y grandes llagas de terrible aspecto después que escocían de tal manera que el enfermo no era capaz de reprimirse, llegando a desgarrarse autolesivamente la piel ${ }^{68}$ : “ $\ddot{\alpha} v \theta \rho \omega \pi o l$

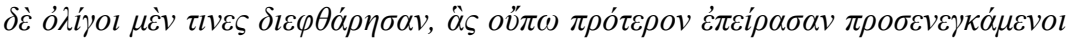

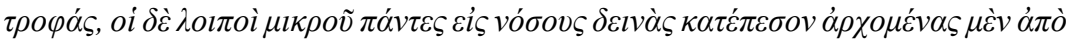

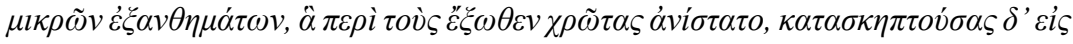

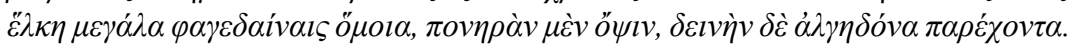

${ }^{64}$ Liv. 4, 52, 2-5.

${ }^{65}$ Liv. 4, 52, 8: "praeterquam ab morbo annonaque nibil eo biennio intestini externiue incommodi fuit. At ubi eae sollicitudines discessere, omnia, quibus turbari solita erat civitas, domi discordia, foris bellum exortum".

${ }^{66}$ Degrassi, Attilio, cit. (n. 38), p. 154.

${ }^{67}$ Liv. 5, 31, 5 ss.: "eodem anno novum bellum cum Volsiniensibus exortum; quo propter famem pestilentiamque in agro Romano ex siccitate caloribusque nimiis ortam exercitus duci nequivit. Ob quae Volsinienses Sappinatibus adiunctis superbia inflati ultro agros Romanos incursavere; bellum inde duobus populis indictum [...] Itaque cum ex senatus consulto consules magistratu se abdicassent, interrex creatur $M$. Furius Camillus, qui P. Cornelium Scipionem, is deinde L. V alerium Potitum interregem prodidit. Ab eo creati sex tribuni militum consulari potestate ut etiamsi cui eorum incommoda valetudo fuisset, copia magistratuum rei publicae esset'.

${ }^{68}$ Dion. Hal. 13, 4, 3-4. 


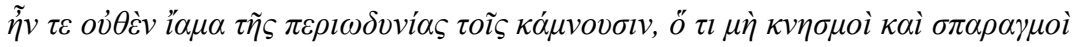

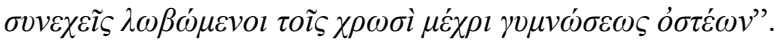

\section{La ceremonia del 'lectisternium' para aplacar la cólera divina en tiempo de epidemia}

Livio relata cómo en el 399 a. C. la crudeza del verano desencadenó una epidemia (gravis pestilensque aestas) de fatales consecuencias para todos (omnibus animalibus). Al no hallarse remedio, se recurrió bajo la supervisión de los duumviri sacris faciundis ${ }^{69}$ al primer lectisternium de la ciudad de Roma (lectisternio tunc primum in urbe Romana facto $)^{70}$, todo un ceremonial que, celebrado en el Capitolio ${ }^{71}$, consistía en disponer con la mayor de las suntuosidades tres mullidos lechos (tribus quam amplissime tum apparari poterat stratis lectis placauere) a disposición de distintas deidades (Apollinem Latonamque et Dianam, Herculem, Mercurium atque Neptunum), que asistían idealmente a tan singular banquete. El ritual se recreaba también en las casas privadas (privatim quoque id sacrum celebratum est), a la par que la ciudad quedaba impregnada por buenos propósitos, brindándose hospitalidad a propios y extraños (notos ignotosque passim advenas in hospitium ductos ferunt), quedando aplazadas las disputas y litigios (iurgiis ac litibus temperatum) y hasta liberándose en aquel periplo a los encadenados (vinctis quoque dempta in eos dies vincula ${ }^{72}$.

Sin embargo, este ceremonial no siempre lograba su propósito, por lo que los romanos se veían abocados a recurrir a otros instrumentos, que, sin embargo, no se alejaban en demasía de las creencias y supersticiones imperantes por aquel entonces. Uno de ellos era la designación de un dictador a quien se encomendaba la conducción de un ritual ancestral consistente en la inserción de un clavo en uno de los muros del templo capitolino dedicado a Júpiter Óptimo Máximo. De ahí toma precisamente su nombre: dictator clavi figendi causa con el supersticioso

\footnotetext{
${ }^{69} \mathrm{~A}$ los que iría dirigido el decreto senatorial para que se consultasen los libros sibilinos en los que previsiblemente se conservaría el ritual, ex Liv. 5, 13, 4. Este ceremonial, de origen griego, tiene un íntimo parentesco con el Iovis epulum, banquete en el que participaban idealmente, junto a Jupiter, Juno y Minerva, así como todo el Senado, siendo este ritual conducido desde comienzos del siglo II a. C. por los tres viri epulones, posteriormente septem viri. Cfr. Cic. de Orat. 3, 72: "sed ut pontifices veteres propter sacrificiorum multitudinem tris viros epulones esse voluerunt, cum essent ipsi a Numa, ut etiam illud ludorum epulare sacrificium facerent, instituti”; Gell. 12, 8, 2: "ea simultas cum diu mansisset et sollemni die epulum Ioui libaretur atque ob id sacrificium senatus in Capitolio epularetur, fors fuit, ut aput eandem mensam duo illi iunctim locarentur"; Liv. 38, 57, 5: "senatum eo die forte in Capitolio cenantem consurrexisse et petisse, ut inter epulas Graccho filiam Africanus desponderet”; y Val. Max. 2.1.2: "[...]: nam Iovis epulo ipse in lectulum, Iuno et Minerva in sellas ad cenam inuitabantur".

${ }^{70}$ También en el 365 a. C. estalló en Roma una epidemia que se extendió por varios años y en la que hubo muchas muertes, con destacadas personalidades entre ellas. Cfr. Liv. 7, 1, 8: "censorem, aedilem curulem, tres tribunos plebis mortuos ferunt, pro portione et ex multitudine alia multa funera fuisse; maximeque eam pestilentiam insignem mors quam matura tam acerba M. Furi fecit"; Liv. 7, 2, 1: "et hoc et insequenti anno C. Sulpicio Petico C. Licinio Stolone consulibus pestilentia fuit”; y Liv. 7, 2, 2: “[...] nisi quod pacis deum exposcendae causa tertio tum post conditam urbem lectisternium fuit".

${ }^{71}$ Liv. 5, 52, 6: "et ne omnia generatim sacra omnesque percenseam deos, in Iovis epulo num alibi quam in Capitolio pulvinar suscipi potest?'.

${ }^{72}$ Liv. 5, 13, 4-8. Cfr. Dion. Hal. 12, 9, 1-3.
} 
propósito de obtener la clemencia divina frente a la tragedia a la que se pretendía hacer frente.

\section{La dictadura 'clavi figendi causa'}

a) Lucius Manlius Imperiossus, dictator clavi figendi causa (365 a. C.)

La ineficacia del lectisternium del 365 a. C. para hacer frente a la epidemia que asolaba Roma y el acrecentamiento del temor popular por un desbordamiento del Tíber ${ }^{73}$, que obligó a interrumpir otros juegos escénicos (teatrales y circenses) que perseguían el mismo propósito disuasorio para los males de la ciudad ${ }^{74}$, condujo al nombramiento de un dictador (Lucio Manlio Imperioso ${ }^{75}$ ) por haber recordado entonces los más ancianos que, en otro tiempo, se recurrió a semejante medida como forma de aplacar una epidemia ${ }^{76}$. Su función, según el relato liviano, inspirado en $\mathrm{Cincio}^{77}$, quedó, por tanto, circunscrita a la mera inserción de aquel clavo ${ }^{78}$, recreando un viejo ritual probablemente de origen etrusco caído en desuso y plasmado en una lex vetusta (de clavo pangendo) ${ }^{79}$, que se practicaba en

${ }^{73}$ Liv. 7, 3, 2: "quin etiam, cum medios forte ludos circus Tiberi superfuso inrigatus impedisset, id vero, velut aversis iam dis aspernantibusque placamina irae, terrorem ingentem fecit".

${ }^{74}$ Liv. 7, 3, 1: "nec tamen ludorum primum initium procurandis religionibus datum aut religione animos aut corpora morbis levavit”. Del juego combinado del lectisternium con la celebración de los juegos nos da cuenta Val. Max. 2, 4, 5: "cuius exemplum Valerius Publicola, qui primus consul fuit, studio succurrendi cinibus secutus apud eandem aram publice nuncupatis notis caesisque atris bubus, Diti maribus, feminis Proserpinae, lectisternioque ac ludis trinoctio factis aram terra, ut ante fuerat, obruit".

${ }^{75}$ Liv. 7, 3, 4: "ea religione adductus senatus dictatorem clavi figendi causa dici iussit; dictus L. Manlius Imperiosus L. Pinarium magistrum equitum dixit’. Degrassi, Attilio, cit. (n. 38), p. 182 lo sitúa en el año 363 a. C.

${ }^{76}$ Liv. 7, 3, 3: "Itaque Cn. Genucio L. Aemilio Mamerco iterum consulibus, cum piaculorum magis conquisitio animos quam corpora morbi adficerent, repetitum ex seniorum memoria diciturpestilentiam quondam clavo ab dictatore fixo sedatam".

${ }^{77}$ Heurgon, Jacques, L. Cincius et la loi du 'clavus annalis', en Athenaeum, 42 (1964), pp. 432 ss. y, con él, Magdelain, André, Praetor maximus et comitiatus maximus, en IV RA., 20 (1969), pp. 257 ss. [= Jus imperium auctoritas. Études de droit romain, Publications de l'École française de Rome (Rome, 1990), pp. 313 ss.], lo identifica como el anticuario L. Cincio, contemporáneo de Varrón, y no con el analista Cincio Alimento.

${ }^{78}$ Liv. 7, 3, 9 refiere precisamente cómo Lucio Manlio fue designado para tan precisa función, por lo que la adopción de otras medidas de corte militar motivó su deposición por parte de los tribunos de la plebe y su subsiguiente enjuiciamiento: "qua de causa creatus L. Manlius, perinde ac rei gerendae ac non solvendae religionis gratia creatus esset, bellum Hernicum adfectans dilectu acerbo inventutem agitavit; tandemque omnibus in eum tribunis plebis coortis seu vi seu verecundia victus dictatura abiit'. Vid. a propósito de esta delimitación del cargo, Milazzo, Antonio, Sul carattere 'straordinario' della magistratura del dittatore: alcune riflessioni su emergenæa e periodicità nella sua nomina, en GAROFALO, Luigi (a cura di), La dittatura romana (Napoli, Jovene Editore, 2017), pp. 247 s. Procchi, Federico, Dittatura e 'provocatio ad populum', en GAROFALO, Luigi (a cura di), La dittatura romana (Napoli, Jovene Editore, 2017), p. 218, sostiene, siguiendo la línea expresada por Nicosia, Giovanni, Sulle pretese figure di 'dictatores inminuto iure', en Studi in onore di Cesare Sanfilippo (Milano, Giuffrè, 1987), VII, pp. 529-592, que la abdicación de aquel dictator clavi figendi causa no descansó realmente en la extralimitación de la medida adoptada en cuanto imminuto iure, sino en "la pressione politica generata dalle laméntele della 'inventus' per 'l'acerbitas' con cui veniva condotto il reclutamento".

${ }^{79}$ Más específicamente sobre esta forma de dictadura puede citarse Mommsen, Theodor, 
el flanco derecho del templo de Júpiter Óptimo Máximo, junto a la cella Minervae, en los idus de septiembre, coincidiendo con el aniversario de su dedicación, con el fin de contabilizar los años transcurridos en una época en la que no era tan frecuente el empleo de la escritura ${ }^{80}$, y que en otro tiempo, atendida la dignidad, solemnidad y trascendencia de un ceremonial que perseguía preservar o restablecer la pax deorum, fue cosa de los magistrados de mayor rango, quizá como parte del ceremonial de su toma de posesión"1: "lex vetusta est, priscis litteris verbisque scripta, ut qui praetor maximus sit idibus Septembribus clavum pangat; fixa fuit dextro lateri aedis Iovis optimi maximi, ex qua parte Minervae templum est. Eum clavum, quia rarae per ea tempora litterae erant, notam numeri annorum fuisse ferunt eoque Minervae templo dicatam legem quia numerus Minervae inventum sit. - Volsiniis quoque clavos indices numeri annorum fixos in templo Nortiae, Etruscae deae, comparere diligens talium monumentorum auctor Cincius adfirmat. - M. Horatius consul ea lege templum Iovis optimi maximi dedicavit anno post reges exactos; a consulibus postea ad dictatores, quia maius imperium erat, sollemne

Die römische Chronologie bis auf Caesar (Berlin, Weidmannsche Buchhandlung, 1859), pp. 176 ss.; Unger, G. F., Der römische Jahresnagel, en Philologus, 32/3 (1873), pp. 531 ss.; SAgLio, Edmond, voz 'clavus', en Daremberg, Charles Victor; Saglio, Edmond, Dictionnaire des Antiquités Grecques et Romaines, (Paris, 1873), I, 2, pp. 1240 ss.; von Premerstein, A., clavus, en PWRE. 7 (Stuttgart, J. B. Metzlerscher Verlag, 1900), col. 2 ss.; Leuze, Oskar, Die römische Jahrzählung. Ein Versuch, ihre geschichtliche Entwicklung zu ermitteln, (Tübingen, Verlag von J. C. B. Mohr, Paul Siebeck, 1909), pp. 159 ss.; TouTAIN, Jules, Le rite de la plantation du clou etudié principalement dans l'antiquité romaine, en Mémoires de la Société Nationale des Antiquaires de France, 25 (1915-1918), pp. 43 ss.; Favaro, G., Il clavus annalis e il dictator clavi figendi causa, en Galazzi Paluzzi, Carlo (a cura di), Atti del I ${ }^{o}$ Congresso Nazionale di Studi Romani (Roma, Licinio Cappelli, 1929), II pp. 223-229; Momigliano, Arnaldo, Ricerche sulle magistrature romane. I. Il 'dictator clavi figendi causa', en Bullettino della Commissione Archeologica Comunale, 58 (1930), pp. 29 ss. [= Quarto contributo alla storia degli studi classici e del mondo antico (Roma, Edizioni di Storia e Letterattura, 1969), pp. 273 ss.]; Hanell, Krister, Sulla questione del clavus annalis, en Bullettino della Commissione Archeologica Comunale di Roma, 58 (1930), pp. 163 ss.; Heurgon, Jaques, cit. (n. 77), pp. 432 ss.; Magdelain, André, cit. (n. 77), pp. 257 ss.; Kaplan, Arthur, cit. (n. 38), pp. 172 s.; PENA, María José, La lex de clavo pangendo, en Hispania Antiqua, 6 (1976), pp. 239 ss.; POMA, Gabriella, Le secessioni e il rito dell'infissione del 'clavus', en Rivista di Storia Antica, 8 (1978), pp. 39 ss.; Aigner Foresti, Luciana, Zur Zeremonie der Nagelschlagung in Rom und in Etrurien, en American Journal of Ancient History, 4/2 (1979), pp. 144 ss.; PINA POLO, Francisco, The consul at Rome. The civil functions of the consuls in the Roman Republic (Cambridge, Cambridge University Press, 2011), pp. 35 ss.; Milazzo, Antonio, cit. (n. 78), pp. 245 ss.; Signorini, Roberto, La 'lex vetusta' di Liv. 7.3.5 e il dittatore 'clavi figendi causa', en Garofalo, Luigi (a cura di), La dittatura romana (Napoli, Jovene Editore, 2017), pp. 357 ss.; Cinaglia, Tiziano, Minerva et Diana, quas ais pariter colendas ovvero, la connotazione lunare di Minerva, en Dialogues d'Histoire ancienne, 45/2 (2019), pp. 225 s.; Rinolfi, Cristiana M. A., Rex, quia potentissimus'. Il re romano tra diritto e religione, en Diritto@Storia, 17 (2019), pp. 39 s. (http:// www.dirittoestoria.it/17/tradizione/Rinolfi-Rex-quia-potentissimus.htm); y MARTínez-PINNA, Jorge, El nacimiento de la república romana (ca. 509-486 A. C.) (Zaragoza, Prensas de la Universidad de Zaragoza, 2020), pp. 260 ss.

${ }^{80}$ Fest., edic. Lindsay, p. 49: "clavus annalis appellabatur, qui figebatur in parietibus sacrarum aedium per annos singulos, ut per eos numerus colligeretur annorum". Vid. Mommsen, Theodor, Die römische Chronologie, cit. (n. 79), pp. 176 ss. y Versnel, H. S., Triumphus. An inquiri into the origin, development and meaning of the roman triumph (Leiden, E. J. Brill, 1970), pp. 271 ss.

${ }^{81}$ Pina Polo, Francisco, cit. (n. 79), p. 37. 
clavi figendi translatum est. Intermisso deinde more digna etiam per se visa res propter quam dictator crearetur" 82 .

El significado de esta versión remozada de tan antiguo ritual, presente también en otras culturas y todavía recurrente en tiempos modernos ${ }^{83}$, puede quizá encontrarse en el hecho de que el clavus, que constituye un elemento capaz de sujetar y dar fijeza a estructuras, actuaría como una especie de talismán capaz de atraer y cargar sobre sí todos los males que la epidemia comportaba. A tal efecto, el clavo se asocia a la idea de estabilidad, no sólo en lo que hace al material empleado para su elaboración considerado en sí mismo (fundamentalmente el hierro, de donde viene el sentido del adjetivo 'férreo'), sino al aspecto funcional que le es propio, esto es, el cierre o clausura que, metafóricamente, admite el sentido de alejamiento o de protección frente a lo externo ${ }^{84}$.

\section{b) Gneo Quinctilius Capitolinus, dictator clavi figendi causa (331 a. C.)}

Bajo el consulado de Marco Claudio Marcelo y Gayo Valerio Potito en el año 331 a. C. ${ }^{85}$, tuvo lugar un episodio tenido inicialmente como un nuevo caso de epidemia que ocasionó muertes por doquier. Livio, frente al relato de otros autores, desvela, sin embargo, la verdadera razón de ser de tan funesto episodio (sicut proditur tamen res, ne cui auctorum fidem abrogaverim, exponenda est), que no fue otro que el evenenamiento orquestado por un grupo de mujeres, sorprendidas por el edil Quinto Fabio Máximo a denuncia de una esclava en plena preparación de venenos por cocción ${ }^{86}$ : "cum primores civitatis similibus morbis eodemque ferme omnes eventu morerentur, ancilla quaedam ad Q. Fabium Maximum aedilem curulem indicaturam se causam publicae pestis professa est, si ab eo fides sibi data esset hand futurum noxae indicium. Fabius confestim rem ad consules, consules ad senatum referunt consensuque ordinis fides indici data. Tum patefactum muliebri fraude civitatem premi matronasque ea venena coquere et, si sequi extemplo velint, manifesto deprehendi posse. Secuti indicem et coquentes quasdam medicamenta et recondita alia invenerunt".

Habiendo comparecido en el foro una veintena de las mujeres denunciadas, entre ellas dos patricias (Sergia y Cornelia), al negar la letalidad de aquellos preparados, fueron invitadas a beber de ellos y, tras ciertos titubeos, se animaron, falleciendo al instante ${ }^{87}$ : "quibus in forum delatis et ad viginti matronis, apud quas de-

${ }^{82}$ Liv. 7, 3, 5-8.

${ }^{83}$ Dungworth, David, Mystifying Roman Nails: clavus annalis, defixiones and minkisi, en Theoretical Roman Archaelogy Journal, s/n (1997, publicado en 1998), pp. 148 ss. y PINA POLO, Francisco, cit. (n. 79), pp. $36 \mathrm{~s}$.

${ }^{84}$ Plin., Nat. 28.63 refiere la costumbre de insertar un clavo en el lugar donde un individuo había padecido un ataque epiléptico como mecanismo para terminar con ella: "clavum ferreum defigere in quo loco primum caput fixerit corruens morbo comitiali absolutorium eius mali dicitur". Vid. LóPEZ Jimeno, Amor; Manuel Mariño, Francisco, Sobre los 'Merseburger Zaubersprüche'y otros textos mágicos, en Epos. Revista de Filología, 9 (1993), p. 496; y Doménech CADALÁs, Fernando, El carácter religioso de la dictadura romana, en SALDVIE, 18-19 (2018-2019), p. 307, n. 14.

${ }^{85}$ Degrassi, Attilio, cit. (n. 38), p. 156.

${ }^{86}$ Liv. 8, 18, 4-7.

${ }^{87}$ Liv. 8, 18, 8-10. 
prehensa erant, per viatorem accitis duae ex eis, Cornelia ac Sergia, patriciae utraque gentis, cum ea medicamenta salubria esse contenderent, ab confutante indice bibere iussae ut se falsum commentam arguerent, spatio ad conloquendum sumpto, cum submoto populo [in conspectu omnium] rem ad ceteras rettulissent, haud abnuentibus et illis bibere, epoto [in conspectu omnium] medicamento suamet ipsae fraude omnes interierunt'. La acción de la justicia no se quedó ahí, sino que apresó a los cómplices de las finadas (comites magnum numerum matronarum indicaverunt) y, posteriormente, se condenó de entre las capturadas a otras ciento setenta matronas (ex quibus ad centum septuaginta damnatae) en lo que vino a ser el primer proceso de envenenamiento de la historia de Roma (neque de veneficiis ante eam diem Romae quaesitum est $)^{88}$.

Sin embargo, por considerarse que la acción concertada de todas aquellas mujeres, más que ordenada a la consecución de un propósito criminal evidenciaba el proceder irracional de unas mentes captae ${ }^{89}$, es decir, literalmente, de unas inteligencias secuestradas por váyase a saber qué afecciones del espíritu, se recurrió a la designación de un dictator clavi figendi causa para que, a través de aquel ritual extraordinario, operase como instrumento de expiación y, con ello, de sanación del espíritu de aquellas matronas ${ }^{90}$. La designación recayó en Gneo Quintilio, el cual, una vez cumplido el ritual, formalizó su renuncia ${ }^{11}$, lo que automáticamente comportaba el restablecimiento del imperium ordinario de los consules.

c) Gaius Petelius Libo Visolus, dictator clavi figendi causa (313 a. C.)

El final del siglo IV a. C. está presidido por persistentes acciones militares en el proceso de expansión de Roma hacia el sur. De ahí que no fuera extraño el recurso a la dictadura como poder extraordinario percibido como de mayor eficiencia. En pleno fragor de la pugna con los samnitas para recuperar las plazas de Fregela y Nola, ocupó el cargo Gayo Petelio ${ }^{22}$, aunque es dudoso, según el relato de Livio, que su designación tuviese un propósito militar. En efecto, señala Livio que la reconquista de Nola pudo ser cosa del cónsul Gayo Junio, de modo que la designación de Gayo Petelio habría obedecido a la necesidad de cumplir el ritual previsto en la vetusta lex de clavo pangendo para alejar los males derivados de una epidemia"3: "Dictator urbis situ circumspecto, quo apertior aditus ad moenia esset, omnia aedificia - et frequenter ibi habitabatur - circumiecta muris incendit; nec ita multo post sive a Poetelio dictatore sive ab C. Innio consule -nam utrumque traditur-Nola est capta. Qui captae decus Nolae ad consulem trabunt, adiciunt Atinam et Calatiam ab eodem captas, Poetelium autem pestilentia orta clavi figendi causa dictatorem dictum".

${ }^{88}$ Liv. 8, 18, 11.

${ }^{89}$ Liv. 8, 18, 12: "prodigii ea res loco habita captisque magis mentibus quam consceleratis similis visa".

${ }^{90}$ Liv. 8, 18, 12: "itaque memoria ex annalibus repetita in secessionibus quondam plebis clauum ab dictatore fixum alienatas[que] discordia mentes hominum eo piaculo compotes sui fecisse, dictatorem clavi figendi causa creari placuit".

${ }^{91}$ Liv. 8, 18, 13: "creatus Cn. Qvinctilius magistrum equitum L. Valerium dixit, qui fixo clauo magistratu se abdicaverunt".

${ }^{92}$ Degrassi, Attilio, cit. (n. 38), p. 156.

${ }^{93}$ Liv. 9, 28, 5-6. 
d) Gnaeus Fulvius Maximus Centumalus, dictator ¿̇clavi figendi causa? (263 a. C.)

El último caso de nombramiento de un dictador supuestamente para conducir el ritual de expiación en el templo de Júpiter Óptimo Máximo lo conocemos a través de los fasti Capitolini, que señalan para el año 263 a. C. a la personalidad de Gneo Fulvio Máximo Centumalo como detentador de esta magistratura extraordinaria en el comienzo de la primera guerra púnica ${ }^{94}$, estando por entonces, según nos cuenta Polibio de Megalópolis, en el desempeño del consulado Manio Otalicio y Manio Valerio ${ }^{95}$, ambos enviados a Sicilia justo un año después del auxilio dispensado por los romanos, capitaneados por el cónsul Apio Claudio, a los mamertinos de Mesina frente a la alianza de cartagineses y los siracusanos de Hierón ${ }^{96}$. Lo cierto es que las fuentes guardan silencio sobre el desempeño de esta magistratura por un hombre que hacía ya mucho tiempo (fue cónsul en el 298 a. C. junto con Lucio Cornelio Escipión Barbado ${ }^{97}$ ) estaba alejado de la primera fila de la política romana. El prestigioso historiador norteamericano Robert Broughton $^{98}$, siguiendo la edición de los Fasti Capitolini de Degrassi ${ }^{99}$, le atribuye la ocupación de este cargo, lo que supondría que, excepcionalmente, los cónsules, desplazados en Sicilia, no habrían cesado en el cargo ${ }^{100}$. Quizá ello pueda explicar que el nombramiento fuese clavi figendi causa, pero no hay traza alguna de que ello se relacionase con un episodio de epidemia en Roma.

${ }^{94}$ Degrassi, Attilio, cit. (n. 38), p. 185.

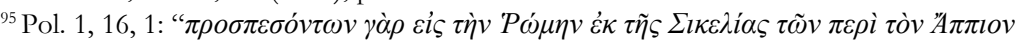

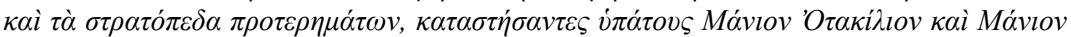

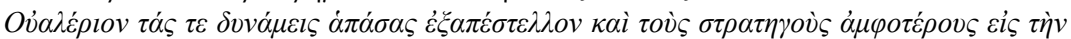

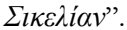

${ }^{96}$ Oros. Hist. 4, 7, 1-2: "anno ab urbe condita CCCCLXXXIII id est Appio Claudio Q. Fabio consulibus Mamertinis, quorum Messana nobilis Siciliae ciuitas erat, auxilia contra Hieronem Syracusanum regem et Poenorum copias Hieroni iunctas et Appium Claudium consulem cum exercitu misere Romani. Qui tam celeriter Syracusanos Poenosque superauit, ut ipse quoque rex rerum magnitudine perterritus ante se uictum quam congressum fuisse prodiderit"; y Eutr., 2.18-19: "et contra Afros bellum susceptum est primum Ap. Claudio Q. Fulvio consulibus. In Sicilia contra eos pugnatum est et Ap. Claudius de Afris et rege Siciliae Hierone triumphavit. Insequenti anno Valerio Marco et Otacilio Crasso consulibus in Sicilia a Romanis res magnae gestae sunt'.

${ }^{97}$ Degrassi, Attilio, cit. (n. 38), p. 157.

${ }^{98}$ Broughton, Robert S., The magistrates of the Roman Republic, I: (509 b.C.-100 b.C.), (New York, American Philological Association Philological Monographs, 1951), p. 204.

${ }^{99}$ Degrassi, Attilio, cit. (n. 38), p. 55, obra posterior a la consultada por Broughton (Fasti consulares et triumphales, en Inscriptiones Italiae XIII,1).

${ }^{100}$ Es en este período recurrente la figura del dictador para reemplazar a los cónsules, imposibilitados de cumplir con sus funciones en Roma. Vid. Humm, Michel, Hiérarchie de pouvoirs et hiérarchie des magistratures dans la Rome républicaine, en BÉRENGER, Agnès y LACHAud, Frédérique (eds.), Hiérarchie de pouvoirs, délégation de pouvoir et responsabilité des administrateurs dans l'Antiquité et au Moyen Âge, Actes du colloque de Metz, 16-18 juin 2011, (Metz, Centre de Recherche Universitaire Lorrain d'Histoire, Université de Lorraine, Site de Metz, 2012), p. 127. 
Agamben, Giorgio, Stato di eccezione (Torino, Bollati Boringhieri, 2003).

Aigner Foresti, Luciana, Zur Zeremonie der Nagelschlagung in Rom und in Etrurien, en American Journal of Ancient History, 4/2 (1979), pp. 144-156.

Broughton, Robert Shannon, The magistrates of the Roman Republic, I: (509 b.C.-100 b.C.) (New York, American Philological Association Philological Monographs, 1951).

CARDILLI, Riccardo, Emergenza e diritto. Il problema della dittattura romana, en CARDILLI, Riccardo; Ciaccia, Mario; Mirabeldi, Cesare (a cura di), Istituzioni, economia, sviluppo. Veccbie e nuovi problema nel dopo emergenza (Roma, Universitalia, 2020), pp. 23-39.

Cassola, Franco; Labruna, Luigi, Il dittattore ed il magister equitum, en Talamanca, Mario (dir.), Lineamenti di storia del diritto romano ${ }^{2}$ (1979, Milano, Giuffrè Editore, 1989).

Castán Pérez-Gómez, Santiago, Cicerón entre el fragor de las luchas políticas: el consulado del 63 a. C. y el debate en torno a la legalidad del senatus consultum ultimum, en Revista Internacional de Derecho Romano, 16 (2016), pp. 270-330.

Cinaglia, Tiziano, Minerva et Diana, quas ais pariter colendas ovvero, la connotazione lunare di Minerva, en Dialogues d'Histoire ancienne 45/2 (2019), pp. 197-236.

Degrassi, Attilio, Fasti Capitolini (Torino, G. B. Paravia \& C., 1954).

De Martino, Francesco, Storia della costituzione romana² (1951, Napoli, Casa Editrice Eugenio Jovene, 1972), I.

Dionysius of Halicarnassus, Roman Antiquities, Volume I-VII (translated by Earnest Cary, Loeb Classical Library, Cambridge, Harvard University Press, 1937-1950).

DoméneCh CADALÁs, Fernando, El carácter religioso de la dictadura romana, en SALDVIE, 18-19 (2018-2019), pp. 305-309.

Dulckeit, Gerhard; Schwarz, Fritz; Waldstein, Wolfgang, Römische Rechtsgeschichte (Neunte Auflage, Munich, C. H. Beck'sche Verlagsbuchhandlung, 1995).

Dungworth, David, Mystifying Roman Nails: clavus annalis, defixiones and minkisi, en Theoretical Roman Archaelogy Journal, s/n (1997, publicado en 1998), pp. 148-159.

Espitia Garzón, Fabio, Dictadura, estado de sitio y provocatio ad populum en la obra de Mommsen, en Revista de Derecho Privado (Universidad Externado de Colombia), 21 (2011), pp. 7-20.

Favaro, G., Il clavus annalis e il dictator clavi figendi causa, en Galassi Paluzzi, Carlo (a cura di), Atti del I $I^{\circ}$ Congresso Nazionale di Studi Romani (Roma, Licinio Cappelli, 1929), II, pp. 223-229.

Gardner, Hunter H., Pestilence and the body politic in latin literature (Oxford, Oxford University Press, 2019).

Greenidge, Abel Hendy Jones, Roman public life (New York, MacMillan and Co., Limited, 1901).

HANELL, Krister, Sulla questione del clavus annalis, en Bullettino della Commissione Archeologica Comunale di Roma, 58 (1930), pp. 163-170.

Heurgon, Jacques, L. Cincius et la loi du 'clavus annalis', en Athenaeum, 42 (1964), pp. 432-437.

Humm, Michel, Hiérarchie de pouvoirs et hiérarchie des magistratures dans la Rome républicaine, en Bérenger, Agnès; Lachaud, Frédérique (eds.), Hiérarchie de pouvoirs, délégation de pouvoir et responsabilité des administrateurs dans l'Antiquité et au Moyen Agge, Actes du colloque de Metz, 16-18 juin 2011 (Metz, Centre de Recherche Universitaire Lorrain d'Histoire, Université de Lorraine, Site de Metz, 2012), pp. 105-134.

Irmscher, Johannes, La dittatura. Tentativo di una storia concettuale, en Meloni, Giovanni 
(a cura di), Dittatura degli antichi e dittatura dei moderni (Roma, Editori Riuniti, 1985), pp. 55-75.

Kaplan, Arthur, Religious Dictators of the Roman Republic, en The Classical World, 67/3 (1973-1974), pp. 172-175.

Kroppenberg, Inge, Law, Religion and Constitution of the Vestal Virgins, en Law \& Literature, 22/3 (2010), pp. 418-439.

Kunschwitz, Peter, Eine kleine Poetik der Seuche. Epidemien im Spiegel römischer Verinschriften, en Gymnasium, 127/2 (2020), pp. 137-157.

LEuze, Oskar, Die römische Jabrzählung. Ein Versuch, ihre geschichtliche Entwicklung zu ermitteln (Tübingen, Verlag von J. C. B. Mohr, Paul Siebeck, 1909).

Liebenam, Wilhelm, Dictator, en PWRE., (Stuttgart, J. B. Metzlerscher Verlag, 1903), I, col. 370-390.

Livy, History of Rome, Volume I-IV (translated by B. O. Foster, Loeb Classical Library, Cambridge, Harvard University Press, 1919-1926).

López Jimeno, Amor; Manuel Mariño, Francisco, Sobre los 'Merseburger Zaubersprüche' y otros textos mágicos, en Epos. Revista de Filología, 9 (1993), pp. 491-510.

LovisI, Claire, Vestale, incestus et juridiction pontificale sous la République romaine, en Mélanges de l'Ecole française de Rome. Antiquité, 110/2 (1998), pp. 699-735.

Luzzatto, Giuseppe Ignazio, Appunti sulle dittature imminuto iure, en Studi in onore di Pietro de Francisci (Milano, Giuffrè Editore, 1956), III, pp. 405-459.

Magdelain, André, Praetor maximus et comitiatus maximus, en IV RA., 20 (1969), pp. 257-286 [= Jus imperium auctoritas. Études de droit romain (Publications de l'École Française de Rome, Rome, 1990), pp. 313-339].

Martínez-Pinna, Jorge, El nacimiento de la república romana (ca. 509-486 A. C.) (Zaragoza, Prensas de la Universidad de Zaragoza, 2020).

Mattiangeli, Daniele, Il ruolo e privilegi delle vestali tra diritto, società, politica e religione. Un esempio unico all'interno dell'ordinamento giuridico romano, en Revista General de Derecho Romano, 19 (2012) pp. 1-28.

Mekacher, Nina; van Haeperen, Françoise, Le choix des Vestales, miroir d'une société en évolution (IIIème s. a. C. - Ier s. p. C.), en Revue de l'Histoire des Religions, 220/1 (2003) pp. 63-80.

Milazzo, Antonio, Sul carattere 'straordinario' della magistratura del dittatore: alcune riflessioni su emergenza e periodicità nella sua nomina, en GAROFALO, Luigi (a cura di), La dittatura romana (Napoli, Jovene Editore, 2017), pp. 231-256.

Momigliano, Arnaldo, Ricerche sulle magistrature romane. I. Il 'dictator clavi figendi causa', en Bullettino della Commissione Archeologica Comunale di Roma, 58 (1930), pp. 29-42 [= Quarto contributo alla storia degli studi classici e del mondo antico (Roma, Edizioni di Storia e Letterattura, 1969), pp. 273-283].

Mommsen, Theodor, Die römische Chronologie bis auf Caesar (Berlin, Weidmannsche Buchhandlung, 1859).

—Römisches Staatsrecht (Leipzig, Verlag von S. Hirzel, 1887), II. 1.

Nicolet, Claude, Dictatorship in Rome, en BAeHr, Peter; Richter, Melvin (ed.), Dictatorship in History and Theory. Bonapartism, Caesarism and Totalitarianism (Whashington D. C., Cambridge University Press, 2004), pp. 263-278.

Nicosia, Giovanni, Sulle pretese figure di 'dictatores inminuto iure', en Studi in onore di Cesare Sanfilippo (Milano, Giuffrè Editore, 1987), VII, pp. 529-592.

MünZER, Friedrich, Die römischen Vestalinnen bis zur Kaiserzeit, en Pbilologus, 92 (1937), pp. 199-222. 
Pelloso, Carlo, La dittatura tra modelo romano,neoromano e italico, en Diritto@Storia. Rivista Internazionale di Scienze Giuridiche e Tradizione Romana, 17 (2019), http:// www.dirittoestoria.it/17/tradizione/Pelloso-Dittatura-modello-romano-neoromano-italico.htm.

Pena, María José, La lex de clavo pangendo, en Hispania Antiqua, 6 (1976), pp. 239-265.

PINA Polo, Francisco, The consul at Rome. The civil functions of the consuls in the Roman Republic (Cambridge, Cambridge University Press, 2011).

Poma, Gabriella, Le secessioni e il rito dell'infissione del 'clavus', en Rivista di Storia Antica, 8 (1978), pp. 39-50.

Procchi, Federico, Dittatura e 'provocatio ad populum', en Garofalo, Luigi (a cura di), La dittatura romana (Napoli, Jovene Editore, 2017), pp. 183-230.

Rinolfi, Cristiana M. A., 'Rex, quia potentissimus'. Il re romano tra diritto e religione, en Diritto (a) Storia. Rivista Internazionale di Scienze Giuridiche e Tradizione Romana, 17 (2019), http://www.dirittoestoria.it/17/tradizione/Rinolfi-Rex-quia-potentissimus.htm.

SAglio, Edmond, voz 'clavus', en Daremberg, Charles Victor; SAglio, Edmond, Dictionnaire des Antiquités Grecques et Romaines (Paris, 1873), I.2, pp. 1238-1242.

SCardigli, Barbara, Vestali integrate nella società romana, en Studia Historica. Historia Antigua, 21 (2003), pp. 97-104.

Schмiтt, Carl, La dittatura. Dalle origini dell'idea moderna di sovranità alla lotta di classe proletaria (Roma-Bari, Universale Laterza, 1975).

SignORInI, Roberto, La 'lex vetusta' di Liv. 7.3.5 e il dittatore 'clavi figendi causa', en GAROFALO, Luigi (a cura di), La dittatura romana (Napoli, Jovene Editore, 2017), pp. 357-379.

Siles VALLEjos, Abraham Santiago, La dictadura en la República romana clásica como referente paradigmático del régimen excepcional constitucional, en Derecho PUCP. Revista de la Facultad de Derecho, Pontificia Universidad Católica de Perú, 73 (2014), pp. 411-424.

ToutaIn, Jules, Le rite de la plantation du clou etudiéprincipalement dans l'antiquité romaine, en Mémoires de la Société Nationale des Antiquaires de France, 25 (1915-1918), pp. 43-80.

Unger, G. F., Der römische Jahresnagel, en Philologus, 32/3 (1873), pp. 531-540.

Ungern-STERnBERg VON PÜRKEL, Jürgen, Untersuchungen zum spätrepublikanischen Notstandrecht. Senatusconsultum ultimum und hostis-Erklärung, (München, C. H. Beck'sche Verlagsbuchhandlung, 1970).

Versnel, Henk S., Triumphus. An inquiri into the origin, development and meaning of the roman triumph (Leiden, E. J. Brill, 1970).

Von Premerstein, Anton, 'clavus', en PWRE. VII (Stuttgart, J. B. Metzlerscher Verlag, 1900), col. 2-4.

WiLCKEN, Ulrich, Zur Entwicklung der römischen Diktatur, en Abhandlungen der Preußischen Akademie der Wissenschaften. Philosophisch-Historische Klasse (Berlin, Akademie der Wissenschaften, de Gruyter in Kommission, 1940), I, pp. 3-32. 